Military Technical College

Kobry El-Kobbah, Cairo, Egypt

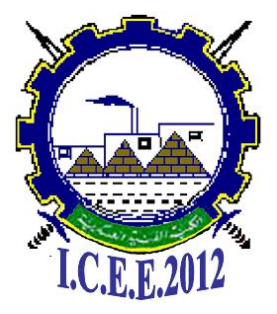

$6^{\text {th }}$ International Conference on

Chemical \& Environmental

Engineering

29 -31 May, 2012.

ENMA-1

\title{
BALLISTIC PROPERTIES PREDICTION FOR VARIANT BUTALITES COMPOSITIONS, AN EASY ABSTENTION TECHNIQUE
}

\author{
W. Abdel-Wareth ${ }^{1}, \mathrm{X} . \mathrm{Xu}^{2}$
}

\begin{abstract}
Ballistic properties for variant Butalites formulations based on Ammonium perchlorate (AP) and hydroxy terminated polybutadiene with some other additives were practically investigated then theoretically predicted. The predictions were investigated for formulations with burning rates ranging from 0.26 to $17.94 \mathrm{~mm} / \mathrm{sec}$ at 70 bar. The predictions were performed using the developments applied to the basic model of multiple flames, the BDP model. The developments were established over the model equations using an easy abstention technique, without multiple flame standoff distances. The results were verified by considering AP regression as the rate-controlling step in combustion, by introducing the additives to the model equations in a passive technique, by the use of a one-dimensionally limited temperature profile to estimate the propellant surface temperature, and by solving the combustion equations iteratively for the mass flux and surface temperature until they reached the required convergence. A computer program was established for obtaining the linear burning rate, surface temperature and other ballistic properties of the previous formulations. The results showed that the predicted linear burning rates were acceptable and verified the international acceptance margins in this field.
\end{abstract}

Key Words: Composite propellants; Combustion; Ballistic properties; Linear Burning rate

1 Egyptian Armed Forces (awae1972000@yahoo.com)

2 Professor (xuxu@buaa.edu.cn)

School of Astronautics, BUAA, Beijing 100191, China 


\section{Introduction}

Investigation of composite propellant burning operations involves complex phenomena occurring in solid, liquid and gas phases where physical and chemical processes that occur during their combustion are not fully understood ${ }^{[1]}$. All ballistic properties predictions (Linear burning rate, pressure exponent and temperature sensitivities) for a composite propellant using one combustion mechanism encounter complicated operations. The linear burning rate represents the base foundation to start any modifications (augmentations) to the solid motor ideal performance due to its design constraints ${ }^{[2]}$. In this paper, linear burning rate prediction means modeling of the combustion phenomenon with steady state burning under zero cross-flow situations over the solid phase, combustion zone and gas phase ${ }^{[3]}$.

The international goal is the development of a universal model, which can predict propellant grain composition from burning rate requirements. This is a tall order in view of the complex competing reactions taking place simultaneously and the problems associated with probing thin reaction zones precisely. Therefore, the problems division into small parts for clearer investigations seems to be an appropriate way to achieve progress in the field. Understanding the combustion of a composite propellant is a serious challenge even without the addition of burning rate modifiers or metallic fuels, and yet it is crucial to understand the former in order to understand the latter. Adding to the complexity of composite propellant combustion is the fact that it is an inherently three-dimensional and intrinsically unsteady system, even when the macroscopic environment is steady. Yet, without complete understanding of all the areas affecting combustion on a microscopic level, no computer code would be able to validate propellant combustion ${ }^{[4-7]}$. Therefore, a return to the fundamentals is necessary and the modifications of a trusty combustion model to verify the international acceptance margins between the theoretical and practical results will be an applicable way.

Performance prediction for composite propellants is very important, as it is the principal method by which the difference between the theoretically predicted and practically evaluated parameters is minimized. The international acceptance margins between the theoretical predictions and practical evaluations must be applied. In this paper, the international acceptance margins are verified if minimum of $90 \%$ of the predicted linear burning rates at 70 bar are within $\pm 10 \%$ error range when compared to the experimental results ${ }^{[8]}$.

The objective of this study was to investigate a technique for the ballistic properties prediction of a specific composite propellant family (specific ingredients with pre-defined specifications) under specific pressure interval. The propellant family (Butalites ${ }^{[9]}$ ) was based on ammonium perchlorate (AP), polyurethane binder (PU), aluminum powder $(\mathrm{Al})$, carbon black $(\mathrm{CB})$, calcium carbonate $\left(\mathrm{CaCO}_{3}\right)$ and copper chromite $(\mathrm{CC})$. The polyurethane binder matrix was composed of hydroxy terminated polybutadiene (HTPB) pre-polymer with anti-oxidant (cyanox), hexamethylene diisocyanate (HMDI) as a curing agent, methyl aziridinyl Phosphine oxide (MAPO) as a bonding agent and diisooctyl azelate (DOZ) as a plasticizer. Herein, our prime importance was to predict the linear burning rates of variant Butalites formulations, without solid motor complexities. The combustion pressure under investigation was defined as 20-120 bar. Our effort involved the use of FORTRAN programs concerning analysis of the propellant solid and gas phases, which was then followed by inspection over the combustion zone modeling modifications with the aid of thermal analytical measurements (TAM), specific surface area measurements and ignition temperature $\left(\mathrm{T}_{\mathrm{ig}}\right)$ measurements. These measurements were applied for the used ingredients and some mixtures. 


\section{Practical data survey}

At this stage, the practical data was divided into two main categories. The first (Table 1) included the practical measurements applied for 20 Butalites formulations. The formulations were prepared (using 1-gallon capacity mixer) according to factors affecting combustion using the previous ingredients. Their burning rates were measured by using the Crawford bomb (Group-A) and $2 \times 4$ ballistic evaluation motor (Group-B) techniques. The second data category (Tables 2 and 3) included the practical measurements applied for the used ingredients. The ingredients were subjected to TAM, differential scanning calorimetry (DSC)/thermal gravimetric analysis (TGA), using the simultaneous analyzer SDT-Q600 V20.5 under dynamic nitrogen atmosphere and heating rate of $40{ }^{\circ} \mathrm{C} / \mathrm{min}$. In addition, the solid ingredients were subjected to specific surface area measurements using the NOVA 2200e-WIN2 V2.1 apparatus where the Brunauer-Emmett-Teller (BET) method was applied. Moreover, special mixtures were subjected to $T_{\text {ig }}$ measurements under heating rate of 40 ${ }^{\circ} \mathrm{C} / \mathrm{min}$. The DSC/TGA digital data were used to determine the decomposition characteristic parameters of the ingredients (heats associated with any process of change, AP kinetic parameters, binder kinetic parameters, AP heat of gasification and binder heat of pyrolysis). The kinetic parameters were calculated by using a simple FORTRAN computer program based on the modified isoconversional method. The calculations were inspected at two intervals. The first was the low conversion interval at 5 to $30 \%$ for both AP and binder. The second was the high conversion interval at 30 to $\sim 70 \%$ for AP and 30 to $\sim 95 \%$ for binder ${ }^{[10 \text {, }}$ ${ }^{11]}$. AP heat of gasification and binder heat of pyrolysis were determined automatically, using the Universal Analysis 2000 data acquisition system linked to the SDT-Q600, on the basis of a hypothetical approach ${ }^{[12]}$. The parameters of AP were investigated as a function of its particle size and for the binder as a function of its formulation curative ratios $[\mathrm{NCO} / \mathrm{OH}(\mathrm{R} 1)$, IMINE/OH (R2) and DOZ/HTPB (R3)].

Table 1 Prepared formulations and their measured results

\begin{tabular}{|c|c|c|c|c|c|c|c|c|c|c|c|c|c|c|}
\hline \multirow[b]{2}{*}{ No. } & \multirow[b]{2}{*}{$\begin{array}{c}\text { Bind } \\
\text { er } \\
\%\end{array}$} & \multirow[b]{2}{*}{$\begin{array}{c}\text { AP } \\
419 . \\
5 \\
\mu \mathrm{m} \\
\%\end{array}$} & \multirow[b]{2}{*}{$\begin{array}{c}\text { AP } \\
175 \\
\mu \mathrm{m} \\
\%\end{array}$} & \multirow[b]{2}{*}{$\begin{array}{c}\mathrm{AP} \\
54 . \\
2 \\
\mu \mathrm{m} \\
\%\end{array}$} & \multirow[b]{2}{*}{$\begin{array}{c}\text { AP } \\
9 \\
\mu \mathrm{m} \\
\%\end{array}$} & \multirow[b]{2}{*}{$\begin{array}{c}\mathrm{Al} \\
11 . \\
5 \\
\mu \mathrm{m} \\
\%\end{array}$} & \multirow[b]{2}{*}{$\begin{array}{c}\mathrm{CC} \\
0.7 \\
5 \\
\mu \mathrm{m} \\
\%\end{array}$} & \multirow[b]{2}{*}{$\begin{array}{c}\mathrm{CaC} \\
\mathrm{O}_{3} \\
14 \\
\mu \mathrm{m} \\
\%\end{array}$} & \multirow{2}{*}{$\begin{array}{c}\mathrm{C} \\
\mathrm{B} \\
10 \\
\mu \\
\mathrm{m} \\
\%\end{array}$} & \multirow[b]{2}{*}{$\begin{array}{c}\rho_{\mathrm{P}} \\
(\mathrm{g} / \mathrm{cm} \\
\left.3{ }^{2}\right)\end{array}$} & \multicolumn{3}{|c|}{$\mathrm{r}$ at $70 \mathrm{bar}(\mathrm{mm} / \mathrm{s})$} & \multirow[b]{2}{*}{$\mathrm{n}$} \\
\hline & & & & & & & & & & & $\begin{array}{r}-30 \\
{ }^{\circ} \mathrm{C}\end{array}$ & $\begin{array}{l}25 \\
{ }^{\circ} \mathrm{C}\end{array}$ & $\begin{array}{l}50 \\
{ }^{\circ} \mathrm{C}\end{array}$ & \\
\hline AI- & 74.5 & & & & 25 & & & & 0. & 1.085 & & 0.26 & 0.36 & 0.1 \\
\hline AI- & 64.5 & & & & 35 & & & & 0 . & 1.174 & & 0.53 & 0.58 & 0.2 \\
\hline AI- & 54.5 & & & & 45 & & & & 0 . & 1.245 & 0.79 & 1.11 & 1.26 & 0.3 \\
\hline AII- & 54.5 & & & 15 & 30 & & & & 0 . & 1.246 & & 1.01 & 1.19 & 0.2 \\
\hline AII- & 54.5 & & & 30 & 15 & & & & 0 . & 1.248 & & 0.89 & 1.02 & 0.3 \\
\hline AIII & 44.5 & & & & 45 & 10 & & & 0 . & 1.351 & 2.17 & 2.56 & 2.82 & 0.2 \\
\hline AIII & 34.5 & & & & 45 & 20 & & & 0. & 1.492 & 3.82 & 4.15 & 4.37 & 0.2 \\
\hline AIV & 51.5 & & & & 45 & & 3 & & 0. & 1.280 & 1.42 & 1.71 & 2.08 & 0.2 \\
\hline AIV & 48.5 & & & & 45 & & 6 & & 0. & 1.339 & 1.85 & 2.36 & 2.81 & 0.2 \\
\hline AV- & 41.5 & & & & 45 & 10 & 3 & & 0. & 1.392 & 2.67 & 3.15 & 3.37 & 0.1 \\
\hline AV- & 38.5 & & & & 45 & 10 & 6 & & 0 . & 1.456 & 3.29 & 3.75 & 4.06 & 0.2 \\
\hline BI-1 & 20 & & 31. & & 31. & 17 & & & & & & 6.81 & & 0.3 \\
\hline BI-2 & 16 & & 33. & & 33. & 17 & & & & & & 7.40 & & 0.3 \\
\hline BI-3 & 12 & & 35. & & 35. & 17 & & & & & & 10.0 & & 0.4 \\
\hline BII- & 14 & 40 & 18 & & 10 & 18 & & & & 1.762 & 6.27 & 6.75 & 6.98 & 0.3 \\
\hline BII- & 14 & 18 & 40 & & 10 & 18 & & & & 1.762 & 6.89 & 7.38 & 7.62 & 0.2 \\
\hline BIII & 19 & & 40 & 20 & 20 & & & & 1 & 1.635 & 6.92 & 7.75 & 8.16 & 0.4 \\
\hline BIII & 18 & & 40 & 20 & 20 & & 1 & & 1 & 1.652 & 10.9 & 11.9 & 12.4 & 0.3 \\
\hline BIII & 18 & & 40 & 20 & 20 & & & 1 & 1 & 1.645 & 6.86 & 7.18 & 7.33 & 0.3 \\
\hline
\end{tabular}




$\begin{array}{lllll}22 & 12 & 34 & 14 & 2\end{array}$


Table 2 Ingredients description, specific surface areas and TAM results

\begin{tabular}{|c|c|c|c|c|c|c|c|c|}
\hline No & $\begin{array}{c}\text { Sample } \\
\text { descripti } \\
\text { on }\end{array}$ & $\begin{array}{l}\text { Practic } \\
\text { al } \\
\text { specifi } \\
\text { c } \\
\text { surface } \\
\left(\mathrm{m}^{2} / \mathrm{g}\right) \\
\end{array}$ & $\begin{array}{c}\text { Theoretic } \\
\text { al } \\
\text { specific } \\
\text { surface } \\
\left(\mathrm{m}^{2} / \mathrm{g}\right)\end{array}$ & $\begin{array}{l}\text { Property } \\
\text { / Value } \\
\text { (cal/g) }\end{array}$ & $\begin{array}{c}\text { (Low) } \\
\text { A } \\
(/ s)\end{array}$ & $\begin{array}{c}\text { (Low) } \\
\mathrm{E} \\
(\mathrm{kcal} / \mathrm{mol} \\
\mathrm{e})\end{array}$ & $\begin{array}{c}\text { (High) } \\
\text { A } \\
(/ \mathrm{s})\end{array}$ & $\begin{array}{c}\text { (High) } \\
\text { E } \\
(\mathrm{kcal} / \mathrm{mol} \\
\mathrm{e})\end{array}$ \\
\hline 1 & $\mathrm{AP}(10$ & 0.56 & 0.31 & $\mathrm{O}_{\mathrm{I}} / 101.9$ & $5.16 \times 1$ & 24.26 & $5.14 \times 10$ & 27.11 \\
\hline 2 & AP $(22.5$ & 0.37 & 0.14 & $\mathrm{Q}_{\mathrm{L}} / 111.0$ & $2.52 \times 1$ & 22.98 & $4.66 \times 10$ & 26.99 \\
\hline 3 & AP $(82.5$ & 0.19 & 0.04 & $\mathrm{Q}_{\mathrm{L}} / 112.7$ & $1.21 \times 1$ & 21.67 & $3.86 \times 10$ & 26.73 \\
\hline 4 & AP (196 & 0.13 & 0.02 & $\mathrm{Q}_{\mathrm{L}} / 117.1$ & $2.86 \times 1$ & 19.24 & $3.25 \times 10$ & 26.51 \\
\hline 5 & AP $(390$ & 0.09 & 0.01 & $\mathrm{Q}_{\mathrm{L}} / 118.3$ & $2.07 \times 1$ & 18.50 & $3.14 \times 10$ & 26.48 \\
\hline 6 & CB (10 & 7.66 & 0.32 & & & & & \\
\hline 7 & Al (11.5 & 0.78 & 0.19 & $\mathrm{~h}_{\mathrm{f}} / 92.3$ & & & & \\
\hline 8 & CC $(0.75$ & 14.94 & 1.29 & & & & & \\
\hline 9 & $\mathrm{CaCO}_{3}$ & 1.65 & 0.16 & $\mathrm{Q}_{\mathrm{caco3}} / 263$ & & & & \\
\hline 10 & PU & & & $\mathrm{Q}_{\text {fuel }}$ & $7.45 \times 1$ & 31.96 & $3.70 \times 10$ & 45.26 \\
\hline 11 & PU & & & $\mathrm{Q}_{\text {fuel }}$ & $1.75 \times 1$ & 29.83 & $3.09 \times 10$ & 44.93 \\
\hline 12 & PU & & & $\mathrm{Q}_{\text {fuel }}$ & $2.20 \times 1$ & 30.21 & $3.24 \times 10$ & 45.02 \\
\hline 13 & PU & & & $\mathrm{Q}_{\text {fuel }}$ & $1.19 \times 1$ & 25.45 & $2.42 \times 10$ & 44.52 \\
\hline
\end{tabular}

Table 3 Special mixtures prepared for $T_{i g}$ measurements and their results

\begin{tabular}{|c|c|c|c|c|c|c|c|c|c|}
\hline No. & $\begin{array}{l}\text { PU-binder } \\
\text { Sample No. } \\
10\end{array}$ & $\begin{array}{c}\mathrm{AP} \\
22.5 \\
\mu \mathrm{m}\end{array}$ & $\begin{array}{l}\mathrm{AP} \\
82.5 \\
\mu \mathrm{m}\end{array}$ & $\begin{array}{l}\mathrm{AP} \\
390 \\
\mu \mathrm{m}\end{array}$ & $\begin{array}{c}\mathrm{CB} \\
10 \\
\mu \mathrm{m}\end{array}$ & $\begin{array}{c}\mathrm{Al} \\
11.5 \\
\mu \mathrm{m}\end{array}$ & $\begin{array}{l}\mathrm{CC} \\
0.75 \\
\mu \mathrm{m}\end{array}$ & $\begin{array}{c}\mathrm{CaCO}_{3} \\
14 \mu \mathrm{m}\end{array}$ & $\begin{array}{c}\mathrm{T}_{\mathrm{ig}} \\
\left({ }^{\circ} \mathrm{C}\right)\end{array}$ \\
\hline $\begin{array}{l}1 \\
2 \\
3 \\
4 \\
5 \\
6 \\
7 \\
8 \\
9 \\
10 \\
11\end{array}$ & $\begin{array}{c}30 \\
50 \\
37.5 \\
30 \\
30 \\
30 \\
30 \\
30 \\
30 \\
30 \\
30\end{array}$ & 62.5 & $\begin{array}{c}50 \\
62.5 \\
70 \\
62.5 \\
50 \\
62.5 \\
62.5\end{array}$ & 70 & 7.5 & 20 & $\begin{array}{l}7.5 \\
7.5\end{array}$ & $\begin{array}{l}7.5 \\
7.5\end{array}$ & $\begin{array}{l}355 \\
356 \\
355 \\
354 \\
353 \\
352 \\
349 \\
317 \\
304 \\
358 \\
362\end{array}$ \\
\hline
\end{tabular}

\section{Solid phase data survey}

At this stage, the propellant solid phase specifications were inspected by creating two FORTRAN computer programs based on the basic international concepts in this field beside basic mathematics and dependent on the raw materials specifications. The first one (Table 4) was concerned with binder composition analysis. It was investigated the binder composition, summary formula, enthalpy of formation and density. The second one (Table 5) was concerned with propellant composition analysis. It was investigated the propellant density, thermal properties ${ }^{[13,14]}$, cast-ability margins ${ }^{[15]}$, fillers volumetric loading factors and surface areas. 
Table 4 Data for $100 \%$ binder compositions

\begin{tabular}{|c|c|c|c|c|c|c|c|c|c|c|}
\hline \multirow{2}{*}{$\begin{array}{l}\text { Binder } \\
\text { formulations }\end{array}$} & \multirow{2}{*}{$\begin{array}{l}\text { Binder } \\
(\%)\end{array}$} & \multirow{2}{*}{$\begin{array}{l}\Delta H_{\text {fuel }} \\
(\mathrm{cal} / \mathrm{g})\end{array}$} & \multicolumn{3}{|c|}{$\begin{array}{l}\text { Main data } \\
\text { estimated }\end{array}$} & \multirow[t]{2}{*}{ НTРВ\% } & \multirow[t]{2}{*}{ HMDI\% } & \multirow[t]{2}{*}{ DOZ\% } & \multirow[t]{2}{*}{ МАРО\% } & \multirow{2}{*}{$\begin{array}{c}\rho_{f} \\
\left(\mathrm{~g} / \mathrm{cm}^{3}\right)\end{array}$} \\
\hline & & & $R_{I}$ & $R_{2}$ & $R_{3}$ & & & & & \\
\hline Group (A) & $34.5 / 74.5$ & -71.2737 & 2 & 0.817 & 0 & 83.6913 & 11.9725 & 0.0 & 4.3362 & 0.9288 \\
\hline Sub-group $(B I)$ & $12-20$ & -194.746 & 0.7 & 0.5 & 0.25 & 75.0876 & 3.7596 & 18.7719 & 2.3809 & 0.9166 \\
\hline Sub-group (BII) & 14 & -193.816 & 0.72 & 0.45 & 0.25 & 75.1858 & 3.8721 & 18.7965 & 2.1456 & 0.9164 \\
\hline Sub-group (BIII) & $18-19$ & -197.958 & 0.825 & 0.6 & 0.25 & 74.2357 & 4.3807 & 18.5589 & 2.8247 & 0.9159 \\
\hline Sub-group (BIV) & 16 & -216.557 & 0.75 & 0.334 & 0.3 & 72.7364 & 3.9020 & 21.8209 & 1.5407 & 0.9157 \\
\hline
\end{tabular}

Table 5 Solid phase analysis results

\begin{tabular}{|c|c|c|c|c|c|c|c|c|c|}
\hline \multirow[b]{2}{*}{ No. } & \multicolumn{2}{|c|}{ Modified idealized surface } & \multirow{2}{*}{$\begin{array}{l}\text { Solid } \\
\text { density } \\
\left(\mathrm{g} / \mathrm{cm}^{3}\right)\end{array}$} & \multirow{2}{*}{$\begin{array}{c}\text { Thermal } \\
\text { conductivity } \\
\text { (cal/cm.s.K) }\end{array}$} & \multirow{2}{*}{$\begin{array}{l}\text { Specific } \\
\text { heat } \\
\text { (cal/g.K) }\end{array}$} & \multicolumn{3}{|c|}{ Initial non-idealized } & \multirow{2}{*}{$\begin{array}{c}\text { Cast- } \\
\text { ability } \\
\text { margins }\end{array}$} \\
\hline & $\frac{\overline{S_{o x}}}{\overline{S_{\circ}}}$ & $\frac{\overline{S_{o x}}}{\overline{S_{o x}}+S_{f}}$ & & & & $\begin{array}{c}\text { Binder } \\
\left(\mathrm{cm}^{2}\right)\end{array}$ & $\begin{array}{c}A P \\
\left(\mathrm{~cm}^{2}\right)\end{array}$ & $\begin{array}{l}\text { Propellant } \\
\left(\mathrm{cm}^{2}\right)\end{array}$ & \\
\hline$A I-1$ & $2.068628 E-$ & $2.187174 E-01$ & 1.0747 & 0.00061 & 0.4696 & 0.842 & 0.353 & 1.288 & within \\
\hline$A I-2$ & $2.968999 E-$ & $3.143678 E-01$ & 1.1436 & 0.00065 & 0.4414 & 0.766 & 0.527 & 1.391 & within \\
\hline$A I-3$ & $3.91 \hat{58} 85 E-$ & $4.152584 E-01$ & 1.2219 & 0.00070 & 0.4133 & 0.679 & 0.723 & 1.508 & within \\
\hline AII- & $3.40 \hat{58} 88 \mathrm{E}-$ & 3.630130E-01 & 1.2219 & 0.00070 & 0.4133 & 0.679 & 0.581 & 1.365 & within \\
\hline$\dot{A} I I-$ & $2.80 \hat{25} 87 E-$ & $3.005231 E-01$ & 1.2219 & 0.00070 & 0.4133 & 0.679 & 0.438 & 1.222 & within \\
\hline ÂIIII- & 3.896̧379E- & $4.707039 E-01$ & 1.3367 & 0.00081 & 0.3807 & 0.593 & 0.791 & 1.734 & within \\
\hline ÁIII- & 3.877̂̉ंÖDE- & $5.432380 E-01$ & 1.4754 & 0.00097 & 0.3481 & 0.490 & 0.873 & 2.008 & within \\
\hline$\hat{A} I V-$ & $2.395 \hat{7} 778 E-$ & 4.301028E-01 & 1.2641 & 0.00073 & 0.4011 & 0.661 & 0.748 & 2.793 & within \\
\hline$\dot{A} I V-$ & $1.72 \hat{58} 28 E-$ & $4.460478 E-01$ & 1.3094 & 0.00077 & 0.3889 & 0.642 & 0.775 & 4.171 & within \\
\hline$\hat{A} V-$ & $2.388 \hat{8} 463 E-$ & $4.898687 E-01$ & 1.3875 & 0.00085 & 0.3685 & 0.570 & 0.821 & 3.154 & within \\
\hline$\dot{A} V-$ & 1.7220̉29E- & $5.106602 E-01$ & 1.4422 & 0.00090 & 0.3563 & 0.545 & 0.854 & 4.686 & within \\
\hline$\hat{B I}-1$ & 4.790̂िं63E- & $6.663880 E-01$ & 1.6559 & 0.00095 & 0.2789 & 0.281 & 0.842 & 1.617 & within \\
\hline$B I-2$ & $5.278049 E-$ & 7.447003E-01 & 1.7217 & 0.00103 & 0.2737 & 0.213 & 0.931 & 1.657 & within \\
\hline$B I-3$ & $5.80 \hat{2} 450 E-$ & $8.314757 E-01$ & 1.7929 & 0.00111 & 0.2685 & 0.139 & 1.027 & 1.701 & boundary \\
\hline BII- & $3.592687 E-$ & $6.332042 E-01$ & 1.7608 & 0.00108 & 0.2708 & 0.178 & 0.462 & 1.197 & within \\
\hline$\dot{B} I I-$ & 3.7930̈89E- & $6.535029 E-01$ & 1.7608 & 0.00108 & 0.2708 & 0.178 & 0.503 & 1.237 & within \\
\hline BIII- & $5.35 \hat{5 \hat{7}} 79 E-$ & $6.947540 E-01$ & 1.6257 & 0.00088 & 0.2825 & 0.233 & 0.796 & 1.370 & within \\
\hline BIII- & $3.968822 E-$ & $7.115514 E-01$ & 1.6505 & 0.00090 & 0.2799 & 0.218 & 0.808 & 1.927 & within \\
\hline$\hat{B} I I I-$ & $5.240839 E-$ & 7.120010E-01 & 1.6449 & 0.00090 & 0.2805 & 0.217 & 0.805 & 1.428 & within \\
\hline$\hat{B I V}$ & $3.433 \hat{1} 32 E-$ & 7.561200E-01 & 1.7293 & 0.00101 & 0.2709 & 0.215 & 0.998 & 2.800 & within \\
\hline
\end{tabular}

\section{Gas phase data survey}

At this stage, the propellant gas phase specifications were inspected using the thermochemical calculations methodology at 70 bar. This stage was very important for the main purpose of this study where, specifications, calculations deviations were not allowed and cannot be practically compared. Therefore, the use of a trusty code, to verify that objective, was more suitable and recommended. The international FORTRAN Code of Gordon and Mc Bride developed by NASA Research Center (CEA-2 Code, 2004) ${ }^{[16]}$ was used to calculate the formulations gas phase characteristic specifications under assigned enthalpy and pressure conditions (Table 6). 
Table 6 Analysis results by the CEA-2 Code at 70 bar

\begin{tabular}{lccc}
\hline & \multicolumn{2}{c}{$\begin{array}{c}\text { Thermal properties assuming frozen } \\
\text { reactions }\end{array}$} & $\begin{array}{c}\text { Combustion } \\
\text { temperature }\end{array}$ \\
\cline { 2 - 3 } & $\begin{array}{c}\text { Conductivity } \times 10^{-3} \\
\text { (cal/cm.s.K) }\end{array}$ & $\begin{array}{c}\text { Specific heat } \\
\text { (cal/g.K) }\end{array}$ & $(\mathrm{K})$ \\
\hline AI-1 & 0.5290 & 0.7926 & 1173.65 \\
AI-2 & 0.5197 & 0.6848 & 1224.20 \\
AI-3. & 0.5017 & 0.5972 & 1273.29 \\
AIII-1 & 0.8862 & 0.6230 & 1918.35 \\
AIII-2 & 1.0759 & 0.6659 & 2368.64 \\
AIV-1 & 0.5000 & 0.5901 & 1279.64 \\
AIV-2 & 0.4980 & 0.5829 & 1286.30 \\
AV-1 & 0.8712 & 0.6405 & 1944.07 \\
AV-2 & 0.8546 & 0.6175 & 1970.64 \\
BI-1 & 0.9448 & 0.5016 & 2813.11 \\
BI-2 & 0.9491 & 0.4997 & 3241.24 \\
BI-3 & 0.9859 & 0.4823 & 3527.42 \\
BII & 0.9965 & 0.4933 & 3409.35 \\
BIII-1 & 0.5970 & 0.4480 & 2425.12 \\
BIII-2 & 0.6006 & 0.4441 & 2497.06 \\
BIII-3 & 0.5983 & 0.4445 & 2483.94 \\
BIV & 0.9105 & 0.4853 & 3169.77 \\
\hline
\end{tabular}

\section{Used technique and BDP model modifications}

\subsection{Principal view}

The burning rate of a solid propellant is primarily influenced by its formulation with the characteristics of each forming component. From the combustion models, the basic Beckstead, Derr and Price (BDP) model using multiple flames ${ }^{[17]}$ appears to be rather satisfying from many points of view. It has been used in many research programs since 1970 [18-22]. There appear, however, certain complexities in the BDP model such as the determination of the standoff distances of the multiple flames that sometimes limit somewhat its day-to-day utility ${ }^{[20]}$. The difficulty here arises as much from the nature of the relevant mathematical expressions as from a lack of precise information regarding the values of the parameters involved. Under such circumstances, it seems worthwhile to make the approach a little more simplified. This will perhaps enable the model liberate itself from its emphasis on the flame standoff distances. No doubt in this process, the technique is liable to become less sophisticated, but it will be easier to operate and this is precisely what may be warranted when new propellants will be developed by their pre-inspected constituents.

The aim of the this stage was to describe modifications of the basic BDP model suitable for such a simplified theory by the use of an easy abstention technique for a known composite propellant family with pre-defined ingredients on the basis of a specific combustion pressure value of 70 bar, covered the interval from 20 to 120 bar.

It was very important to clarify the following points:

1) The problem was handled separately for each formulation over its solid phase (zone-1), combustion zone [zone-2, decomposition phase (at the combustion sub-surface) and condensed phase (solid gas interface, at or just above the combustion surface)] and gas phase (zone-3).

2) The BDP model simplified theory was concerned with the carelessness of both flame standoff distances and dependence of the flame structure on AP particle size. 
3) The physical meaning of the applied modifications was the treatment methodology of the multi-modal AP systems, CB, Al and burning rate modifiers incorporation into the model equations.

4) This problem was treated by the use of a one-dimensional limited temperature profile, (the limitation here means that it was not dependent on the reaction zones thicknesses), Figure $1^{[4,23]}$.

5) The multi-modal oxidizer surface areas were mainly based on the practical data applied by the BET-method using the Sauter mean diameter for each AP grade involved in each formulation.

\subsection{Combustion zone treatments}

It was very important to apply a clear treatment technique for the measured parameters and calculated specifications to be ready for the required applications using the basic BDP model modifications at the combustion zone. This objective was achieved by the collection of each set of data to form the best-fit equation describing it. The treatment technique for the 20 Butalites formulations was achieved by the following steps (Figure 1):

1) For the solid phase, far inside the propellant ( $T \approx T_{0}$, initial temperature), the specifications introduced as they were calculated (from the solid phase data survey). At the solid-phase/decomposition-phase imaginary boundary interface, the thermal properties were corrected under the assumption of a constant propellant solid density. This principle formed an approach to the propellant combustion surface. The boundary interface temperature was suggested to, approximately, equal the average value between $\mathrm{T}_{\mathrm{o}}$ and $\mathrm{T}_{\mathrm{s}}$ (surface temperature) and named the decomposition temperature $\mathrm{T}_{\mathrm{d}}$.

2) To reach the solid phase thermal properties at $T \approx T_{d}$ and to keep away from the complicated heat transfer mechanisms, an abridged method was used. It was based on the trusty definition of each thermal property versus temperature for each material involved in the propellant matrix ${ }^{[14]}$. Thus, we recalculated the propellant thermal properties at $T \approx T_{d}$ using the solid phase programs. For the interval $T \approx T_{d} \sim T_{s}$, the decomposition characteristic parameters were treated and evidently presented at Appendix 1.

3) For the gas phase, far outside the propellant combustion surface $\left(T \approx T_{f}\right.$, flame temperature), the specifications introduced as they were calculated (from the gas phase data survey).

4) To reach the gas phase thermal properties at $\mathrm{T} \approx \mathrm{T}_{\mathrm{fs}}$ (as an approach to the combustion surface) and to keep away from the complicated heat transfer mechanisms, also an abridged method was used. For each formulation, interpolations were used to describe each property variation (from $\mathrm{T}_{\mathrm{f}}$ to $\mathrm{T}_{\mathrm{s}}$ ) for an imaginary temperature value near the combustion surface. Thus, it was easily applied to define the property variation at any temperature within the predefined interval. The imaginary temperature approach $\left(\mathrm{T}_{\mathrm{fs}}\right)$ was assumed to have an incremental value, approximately, equal to the same difference between $\mathrm{T}_{\mathrm{s}}$ and $\mathrm{T}_{\mathrm{d}}$ :

$$
\mathrm{T}_{\mathrm{fs}} \approx 2 \mathrm{~T}_{\mathrm{s}}-\mathrm{T}_{\mathrm{d}}
$$




\subsection{Ingredients incorporation}

We applied systematic modifications to the basic BDP model combustion equations ${ }^{[17]}$. Following the BDP model:

\subsubsection{AP/PU-binder based propellant}

Mass burning rate was re-expressed as an averaged one-step Arrhenius function for different AP grades $\left(\overline{m_{o x}}\right)$ :

$$
\overline{m_{o x}}=\sum_{i=1}^{n} \alpha_{o x_{i}} m_{o x_{i}}=\sum_{i=1}^{n} \alpha_{o x_{i}} \rho_{o x} r_{o x_{i}}=\sum_{i=1}^{n} \alpha_{o x_{i}} A_{o x_{i}} \exp \left(-E_{o x_{i}} / R T_{s}\right)
$$

The surface temperature $T_{s}$ was assumed uniform and obtained from an energy balance at the propellant combustion surface. Thus,

$$
\begin{gathered}
m_{T} C_{p}\left(T_{s}-T_{\circ}\right)=-\overline{m_{o x}} \frac{\overline{S_{o x}}}{S_{\circ}} \overline{Q_{L}}-m_{f} \frac{S_{f}}{S_{\circ}} Q_{f u e l}+\beta_{F} Q_{P F} m_{T} \exp \left(-\xi_{P F}^{*}\right) \\
+\left(1-\beta_{F}\right) \overline{m_{o x}} \times \frac{\overline{S_{o x}}}{S_{\circ}}\left[\overline{Q_{A P}} \exp \left(-\overline{\xi_{A P}^{*}}\right)+Q_{F F} \exp \left(-\xi_{F F}^{*}\right)\right]
\end{gathered}
$$

Where:

$$
\begin{aligned}
& \overline{\frac{S_{o x}}{S_{\circ}}}=\sum_{i=1}^{n} \frac{\alpha_{o x_{i}} S_{o x_{i}}}{S_{\circ}} \\
& \overline{Q_{L}}=\sum_{i=1}^{n} \alpha_{o x_{i}} Q_{L_{i}} \\
& \overline{Q_{A P}}=C_{A P}\left(T_{A P}-T_{\circ}\right)+\overline{Q_{L}}
\end{aligned}
$$

Equation (3) described the heat transferred from the various flame fronts (the pre-mixed AP monopropellant flame, the primary flame between the decomposition products of the oxidizer and the binder, and the final diffusion flame between the products of the monopropellant flame and the binder decomposition products) to the solid surface as presented at Figure 2. The multiplying factor represented the heat flux generated by the flame front, while the exponential function represented the generated heat conducted fraction back to the combustion surface. The parameters $\overline{S_{o x}}, \overline{Q_{L}}, \overline{Q_{A P}}$ and $\overline{\xi_{A P}^{*}}$ related to the averaged values of the multi-modal AP systems.

To overcome the uncertainties in the determination of the various parameters occurring in the BDP model flame equations, it was assumed as suggested by Summerfield et al ${ }^{[20,24]}$ that the overall heat feedback from the flamelets to the surface in the combustion of a non-aluminized propellant is approximately 1.25 times that from the AP monopropellant flame. Under these conditions, Equation (3) was modified to the simpler form:

$$
m_{T} C_{p}\left(T_{s}-T_{\circ}\right)=-\overline{m_{o x}} \frac{\overline{S_{o x}}}{S_{\circ}} \overline{Q_{L}}-m_{f} \frac{S_{f}}{S_{\circ}} Q_{f u e l}+1.25\left(1-\beta_{F}\right) \overline{m_{o x}} \times \frac{\overline{S_{o x}}}{S_{\circ}} \times \overline{Q_{A P}} \exp \left(-\overline{\xi_{A P}^{*}}\right)
$$

From the relation:

$$
m_{T}=\left(\overline{m_{o x}} / \alpha\right)\left(\frac{\overline{S_{o x}}}{S_{\circ}}\right)=\left(\frac{m_{f}}{(1-\alpha)}\right)\left(\frac{S_{f}}{S_{\circ}}\right)
$$

Then by substitution into Equation (7) and solution for $\mathrm{T}_{\mathrm{s}}$, the result was:

$$
T_{s}=T_{\circ}-\alpha \frac{\overline{Q_{L}}}{C_{p}}-(1-\alpha) \frac{Q_{\text {fuel }}}{C_{p}}+1.25\left(1-\beta_{F}\right) \alpha \times \frac{\overline{Q_{A P}}}{C_{p}} \exp \left(-\overline{\xi_{A P}^{*}}\right)
$$

Where $\overline{\xi_{A P}^{*}}$ was given by the gas phase kinetic equation:

$\overline{\xi_{A P}^{*}}=C_{P}{\overline{m_{o x}}}^{2} / \lambda k_{A P} P^{\delta}$ 
The reaction rate constant KAP in Equation (10) is an Arrhenius function for the oxidizer dependent on pressure, AP flame temperature and the reaction order $(\sigma)$. KAP is (calculated from known, well-inhibited samples, AP burning rates at 70 atm [3, 17 and 18]) reported in many references by the value $1.12 \mathrm{~g} / \mathrm{cm} 3 \mathrm{~s}$ atm $(1.8)$.

To keep away from the standoff distances determinations was a principle in this study. At the same time, the value of $\beta_{\mathrm{F}}$ was dependent on these flame heights in the BDP model. Therefore, another acceptable solution for this problem was required. $\beta_{F}$ values of a typical AP/PS and AP/PU based propellants with $70 \%$ AP loadings $(\alpha=0.7$, for different AP sizes from 5 to $310 \mu \mathrm{m})$ and different pressures up to 1000 psi were recorded ${ }^{[25]}$.

To make a connection between these data and our requirements where the structural mode of the HTPB pre-polymer with HMDI in this study represented a PU matrix, the relationship between the pressure $[\mathrm{X}(\mathrm{psi})]$ and $\beta_{\mathrm{F}}[\mathrm{Y}](\alpha=0.7)$ was fitted to the following equation:

$Y=307.45 X^{-1.3113} \rightarrow R^{2}=0.9946$

Thus, for any formulation at the interval of 20-120 bar, the new $\left(\beta_{\mathrm{F}}\right)$ value (say $\beta_{\mathrm{F}}{ }_{\mathrm{F}}$ ) corresponded to any new $\operatorname{AP}(\alpha)$ value (say $\alpha^{*}$ ) was obtained from the equation:

$$
\beta_{F}^{*}=\beta_{F}\left(\frac{1-\alpha^{*}}{1-\alpha}\right) \frac{\alpha}{\alpha^{*}}
$$

Equations (2, 9, and 10) were solved simultaneously for the AP mass flux, surface temperature, and AP non-dimensional flame stand of distance. The mass flux averaged over the entire propellant surface, where the oxidizer regression was considered as the ratecontrolling step in combustion, was represented by:

$$
m_{T}=\left(\overline{m_{o x}} / \alpha\right) \times\left(\overline{S_{o x}}\right)
$$

Thus, linear burning rate (r) evaluation for the propellant was given by:

$$
r=m_{T} / \rho_{P}
$$

Treatment of the oxidizer to propellant surface ratio $\left(\mathrm{S}_{\mathrm{ox}} / \mathrm{S}_{\mathrm{o}}\right)$ was started from the initial data listed at Table 5. the $\mathrm{S}_{\mathrm{ox}} / \mathrm{S}_{\mathrm{o}}$ was based on the solid ingredients specific surface measurements and the assumption that the homogeneously mixed AP particles for each grade incorporated in the propellant were spheres with initial Sauter mean diameter $D_{\mathrm{oi}}$. This surface was assumed as the non-idealized one before combustion to feel formulation effect on the geometry data.

The previously measured specific surface areas by the BET-method for the solid ingredients cannot be compared to their theoretically determined values (Table 2). Therefore, the start from a criterion based on fixed surface parameters under assumed conditions (specific geometry and pressure) provided us with the required light to handle this situation.

The factor $\mathrm{h} / \mathrm{D}_{\mathrm{o}}$ in the BDP model represented the fractional distance the oxidizer protruded above or recessed below the surface. It was written by the following equation:

$$
\begin{aligned}
& \frac{h}{D_{\circ}}=\frac{1}{2}\left(1 \pm \frac{1}{(3)^{1 / 2}}\right)\left(1-\frac{r_{o x}}{r_{f}}\right)+r_{o x} \frac{t_{i g n}}{D_{\circ}} \\
& \underline{\text { Where }} t_{i g n}=C_{i g n} \frac{D_{\circ}^{m^{*}+1}}{P^{n^{*}}} \quad \underline{\text { and }} \quad r_{f}=A_{f} \exp \left(-E_{f} / R T_{s}\right)
\end{aligned}
$$

Many experimental studies indicated that $h / D_{0}$ might be positive at low pressures, zero somewhere in the range of 300 to 600 psi and negative at higher pressures ${ }^{[17,26]}$. In addition, in the BDP model, variations in the value of oxidizer to propellant surface ratio were determined to have a minor effect on the burning rate curve. Varying $t_{\text {ign }}$ in Equation (15) over a very large range of values had a significant effect on the calculated values of $h / D_{o}$, a lesser effect on the value of $S_{o x} / S_{o}$ and virtually no effect on the burning rate. Thus, the parameters involved only in Equation (15), (i.e. $\mathrm{A}_{\mathrm{f}}, \mathrm{E}_{\mathrm{f}}$ and $\mathrm{t}_{\mathrm{ign}}$ ), had such a small influence on the burning rate that the particular value used for these parameters was not important. These 
parameters were adjusted to give consistent values of $h / \mathrm{D}_{\mathrm{o}}{ }^{[17]}$. Therefore, the start from an AP particle domed over or recessed under the binder surface by the value $\approx 0.25$ then idealizing it represented our suggested solution for this problem (Figure 3).

The previous suggestion was applied for each AP grade through an imaginary approach based on the conversion of the particle spherical geometry to a cylindrical one with the same diameter $\mathrm{D}_{\mathrm{oi}}$ and corrected length of $\left[(2 / 3) \mathrm{D}_{\mathrm{oi}}\right]$. Then, the initial particle volume maintained constant. Under the assumption of unchanged binder volume, the oxidizer volumetric loading fraction was not changed. This operation followed by the definition of a fixed surface unit based on the maximum AP grade diameter $\left[(2 / 3) \mathrm{D}_{\max }\right]$ in the mixture matrix as the main combustion-controlling factor. This controlling factor was internally controlled by the repeated AP minimum grade diameter $\left[(2 / 3) \mathrm{D}_{\min }\right]$. Thus, the mixture surface was not represented by the initial area only but by the accumulated surfaces inside its fixed unit. In addition, the accumulated binder surface was a function of its initial value multiplied by the number of its layers inside the fixed unit $\left(D_{\max } / D_{\min }\right)$. The accumulated surfaces in this fixed unit were assumed as the effective surface. This effective surface represented the instantaneous average combustion geometry where the $S_{o x} / S_{o}$ values were calculated according to it. A modification was added to the second solid phase FORTRAN program to calculate the effective accumulated surface for each propellant formulation then to estimate the $S_{\text {ox }} / S_{0}$ average ratio (Table 5).

To make a reasonable connection between the BDP model and the previous suggestion, Equation (15) was used to calculate the value of $\mathrm{h} / \mathrm{D}_{\mathrm{o}}$ for each formulation at 20-120 bar followed by correction of the calculated $\mathrm{S}_{\mathrm{ox}} / \mathrm{S}_{\mathrm{o}}$ values that based on $\mathrm{h} / \mathrm{D}_{\mathrm{o}} \approx 0.25$. The values of $t_{\text {ign }}$ were based on $C_{\text {ign }}$ value of $190 \mathrm{~s} \mathrm{~atm}{ }^{(0.72)} / \mathrm{cm}^{(1.8)}$, as derived by Shannon ${ }^{[18]}$. Thus, the BDP model principle was partially applied and effect of the measured specific surface areas was prevailed (introduced and corrected). In case of additives incorporation to the AP/PUbinder matrix, $\alpha$ was represented the ratio of the oxidizer to oxidizer-fuel binder combination and the $S_{o x} / S_{o}$ ratio was modified to the oxidizer to oxidizer-fuel binder combination surface ratio (Table 5). Then, Equation (13) was modified to the following form:

$$
m_{T}=\left(\overline{m_{o x}} / \alpha\right) \times\left(\overline{\overline{S_{o x}}+S_{f}}\right)
$$

\subsubsection{CB incorporation}

As a stable material up to about $4000 \mathrm{~K}$, during combustion of the propellant contained $\mathrm{CB}$, it was assumed that $\mathrm{CB}$ solid particles were heated up to the propellant surface temperature then leaved the combustion surface with the reacted AP/binder matter to the gas phase with an extremely low burning rate. Thus, Equation (9) was modified to the form:

$$
\left(T_{s}-T_{\mathrm{o}}\right) \cdot\left(1+\frac{m_{C B}}{m_{T}} \cdot \frac{C_{C B}}{C_{P}}\right)=-\alpha \frac{\overline{Q_{L}}}{C_{p}}-(1-\alpha) \frac{Q_{\text {fuel }}}{C_{p}}+1.25\left(1-\beta_{F}\right) \alpha \times \frac{\overline{Q_{A P}}}{C_{p}} \exp \left(-\overline{\xi_{A P}^{*}}\right)
$$

The ratio $\mathrm{m}_{\mathrm{CB}} / \mathrm{m}_{\mathrm{T}}$ was replaced by the $\mathrm{CB}$ effective loading fraction to the oxidizer-fuel binder combination $\alpha_{\mathrm{CB}}$. Then, Equation (17) was modified to the form:

$$
\left(T_{s}-T_{\mathrm{o}}\right) \cdot\left(1+\alpha_{C B} \cdot \frac{C_{C B}}{C_{p}}\right)=-\alpha \frac{\overline{Q_{L}}}{C_{p}}-(1-\alpha) \frac{Q_{\text {fuel }}}{C_{p}}+1.25\left(1-\beta_{F}\right) \alpha \times \frac{\overline{Q_{A P}}}{C_{p}} \exp \left(-\overline{\xi_{A P}^{*}}\right)
$$

\subsubsection{Al-powder incorporation}

Metal combustion does not usually contribute much to the burning rate of the propellant itself because most of the heat release occurs far from the propellant surface. However, as with most generalizations about metal behavior, this one was violated by propellant compositions with oxidizers containing fluorine ${ }^{[27]}$. The effect of aluminum addition on the burning rate of 
propellant is difficult to validate because of the several competing factors that are called into play and any combustion modeling effort in respect of an aluminized propellant has, on necessity, to be based on a specific hypothesis regarding the role of aluminum. While, many of the experimentally proved hypotheses are needy for real burning atmospheres, not oxidizing gases ${ }^{[28]}$. In addition, a study is cleared that Al not affect AP decomposition ${ }^{[29]}$.

We were assumed that, during aluminized propellant combustion, the aluminum particles were heated up to the propellant surface temperature and melted at the condensed phase. The molten metal was presented in the gaseous phase in an agglomerated state. Its combustion was rather slow, taking place probably at some distance downstream of the gaseous reaction zone of the propellant. This assumption can be applied for the micrometer-size aluminum only because it has been proved that the nanometer-size powder combustion begins at temperatures lower than $\mathrm{Al}$ melting point by about 200 to $300{ }^{\circ} \mathrm{C}{ }^{[30]}$. Thus, the assumption suggested by Summerfield for the non-aluminized propellants was also applied for this proposed hypothesis of aluminum combustion. The addition of aluminum powder in any propellant is likely to result in a higher heat flux from the gaseous phase to the solid surface. The increased heat flux increases owing to the steeper temperature gradient, the increased thermal conductivity of the combustion products and the lowered average heat capacity of the solid ${ }^{[28]}$. When all of these effects were incorporated into Equation (18), it was modified to the following form:

$$
\begin{gathered}
\left(T_{s}-T_{\mathrm{o}}\right) \cdot\left(1+\frac{m_{A l}}{m_{T}} \cdot \frac{C_{A l}}{C_{p}}+\alpha_{C B} \cdot \frac{C_{C B}}{C_{p}}\right)=-\frac{m_{A l}}{m_{T}} \cdot \frac{h_{f}}{C_{p}}-\alpha \frac{\overline{Q_{L}}}{C_{p}}-(1-\alpha) \frac{Q_{\text {fuel }}}{C_{p}} \\
+1.25\left(1-\beta_{F}\right) \alpha \times \frac{\overline{Q_{A P}}}{C_{p}} \exp \left(-\overline{\xi_{A P}^{*}}\right)
\end{gathered}
$$

The ratio $\mathrm{m}_{\mathrm{Al}} / \mathrm{m}_{\mathrm{T}}$ was replaced by the $\mathrm{Al}$ effective loading fraction to the oxidizer-fuel binder combination $\alpha_{\mathrm{Al}}$. Then, Equation (19) was modified to the form:

$$
\begin{aligned}
& \left(T_{s}-T_{\circ}\right) \cdot\left(1+\alpha_{A l} \cdot \frac{C_{A l}}{C_{p}}+\alpha_{C B} \cdot \frac{C_{C B}}{C_{p}}\right)=-\alpha_{A l} \cdot \frac{h_{f}}{C_{p}}-\alpha \frac{\overline{Q_{L}}}{C_{P}}-(1-\alpha) \frac{Q_{\text {fuel }}}{C_{P}} \\
& +1.25\left(1-\beta_{F}\right) \alpha \times \frac{\overline{Q_{A P}}}{C_{P}} \exp \left(-\overline{\xi_{A P}^{*}}\right)
\end{aligned}
$$

\subsection{4 $\mathrm{CaCO}_{3}$ and $\mathrm{CC}$ incorporation}

Representative methods to control the burning rate of composite propellants used the date including adding a combustion accelerator or moderator. It is well known that the burning rate of these propellants, which contain AP, is enhanced when some transition metal oxides (TMO'S) like CC and $\mathrm{Fe}_{2} \mathrm{O}_{3}$ used, and reduced with some alkaline salts like $\mathrm{LiF}$, or $\mathrm{CaCO}_{3}$. Although many researchers have proposed various theories as to how the TMO'S enhance the burning rate, the mechanism remains unclear ${ }^{[31]}$. The same phenomenon accompanies the moderators too ${ }^{[32,33]}$.

The previous measurement results of the ignition temperatures (Table 3) were assumed as an applicable guide to explore this problem (Figure 4 describes mass loss profiles for some mixtures). The $T_{i g}$ data related to the sudden degradation steps for each mixture showed that, $\mathrm{CC}$ addition over the same AP size was effective (lowered the $\mathrm{T}_{\mathrm{ig}}$ ) and became more vigorous with lower AP size. On the other hand, $\mathrm{CaCO}_{3}$ addition over the same AP size was neglected (elevated the $\mathrm{T}_{\mathrm{ig}}$ ) and had a slight effect with lower AP size.

These data reinforced the assumptions that with burning rate accelerators the AP mass flux will be enhanced by lowering the activation energy required to start its regression then increases its sensitivity to heat according to its particle size and accelerator content ${ }^{[31]}$. In addition, in case of $\mathrm{CaCO}_{3}$, the strong endothermic process $\left(\mathrm{Q}_{\mathrm{CaCO} 3}\right)$ to be pertinent to the possible cooling at or just above the combustion surface that results in burning depression ${ }^{[33]}$. Thus, we were assumed that: 
a) $\mathrm{CaCO}_{3}$ particles were heated to the surface temperature then decomposed or leaved and decomposed to $\mathrm{CaO}$ very close to the combustion surface. Therefore, solid $\mathrm{CaO}$ particles were continued to the gas phase far from the combustion surface. Under this assumption, Equation (20) was modified to the following form:

$$
\begin{gathered}
\left(T_{s}-T_{\mathrm{o}}\right) \cdot\left(1+\alpha_{\mathrm{CaCO}_{3}} \cdot \frac{C_{C a C O_{3}}}{C_{p}}+\alpha_{A l} \cdot \frac{C_{A l}}{C_{p}}+\alpha_{C B} \cdot \frac{C_{C B}}{C_{p}}\right)=-F_{C_{C a C O}} \cdot \frac{Q_{C a C O_{3}}}{C_{p}}-\alpha_{A l} \cdot \frac{h_{f}}{C_{p}}-\alpha \frac{\overline{Q_{L}}}{C_{p}} \\
-(1-\alpha) \frac{Q_{\text {fuel }}}{C_{p}}+1.25\left(1-\beta_{F}\right) \alpha \times \frac{\overline{Q_{A P}}}{C_{p}} \exp \left(-\overline{\xi_{A p}^{*}}\right)
\end{gathered}
$$

Where:

$$
F_{\mathrm{CaCO}_{3}}=\frac{M_{\mathrm{CaO}}}{M_{\mathrm{CaCO}_{3}}} \cdot \alpha_{\mathrm{CaCO}_{3}}
$$

b) CC ultra fine particles $(0.75 \mu \mathrm{m})$ were covered the AP particles and both of them heated to the surface temperature. Under its catalytic effects, CC leaded to AP decomposition with higher mass flux. Therefore, $\mathrm{CC}$ particles were ejected to the gas phase far from the surface. Then, Equations (21 and 2) were modified to the following forms:

$$
\begin{aligned}
& \left(T_{s}-T_{\mathrm{o}}\right) \cdot\left(1+\alpha_{C C} \cdot \frac{C_{C C}}{C_{p}}+\alpha_{C_{C a C O}} \cdot \frac{C_{C_{C a C O}}}{C_{p}}+\alpha_{A l} \cdot \frac{C_{A l}}{C_{p}}+\alpha_{C B} \cdot \frac{C_{C B}}{C_{p}}\right)=-F_{C_{C C O}} \cdot \frac{Q_{C a C O}}{C_{p}} \\
& -\alpha_{A l} \cdot \frac{h_{f}}{C_{p}}-\alpha \frac{\overline{Q_{L}}}{C_{p}}-(1-\alpha) \frac{Q_{f u c l}}{C_{p}}+1.25\left(1-\beta_{F}\right) \alpha \times \frac{\overline{Q_{A P}}}{C_{p}} \exp \left(-\overline{\xi_{A P}^{*}}\right) \\
& \overline{m_{o x}}=\sum_{i=1}^{n} \alpha_{o x_{i}} A_{o x_{i}} \exp \left(-E_{o x_{i}} \cdot F_{c C_{i}} / R T_{s}\right)
\end{aligned}
$$

The factor $\mathrm{F}_{\mathrm{CCi}}$ was evaluated on the basis of the previous $\mathrm{T}_{\mathrm{ig}}$ data and defined as the ratio of $\mathrm{T}_{\text {ig }}$ measured for $(7.5 \% \mathrm{CC} \times 62.5 \% \mathrm{AP})$ to $\mathrm{T}_{\mathrm{ig}}$ measured without $\mathrm{CC}$. To make a connection to our requirements, the relationship between AP particle sizes $[\mathrm{X}(\mu \mathrm{m})]$ and the measured specific surface areas $\left[\mathrm{Y}\left(\mathrm{m}^{2} / \mathrm{g}\right)\right]$ by the BET-method was fitted to:

$Y=1.732032 X^{-0.4952952} \rightarrow R^{2}=0.9994$

In addition, the relationship between AP specific surface areas $\left[X\left(\mathrm{~m}^{2} / \mathrm{g}\right)\right]$ and $\mathrm{F}_{\mathrm{CCi}}[\mathrm{Y}]$ was fitted to:

$Y=0.9366 \exp (-0.2437 X) \rightarrow R^{2}=0.9997$

Thus, to apply for any formulation with known $\mathrm{AP}_{\mathrm{i}}$ specific surface area, the new $\mathrm{F}_{\mathrm{CC}}$ value (say $\mathrm{F}^{*} \mathrm{CCi}_{\mathrm{i}}$ ) corresponded to any other effective $\mathrm{CC}$ fraction $\left(\mathrm{CC}_{\mathrm{ef}}\right), \rightarrow\left(\mathrm{CC} \% \times \mathrm{AP}_{\mathrm{i}} \%\right)$, value (say $\mathrm{CC}^{*}{ }_{\text {ef }}$ ) was obtained by:

$$
F_{c c_{i}}^{*}=F_{c c_{i}}-\left[\left(C C_{e f}-C C_{e f}^{*}\right) \cdot\left(F_{c c_{i}}-1.0\right) / C C_{e f}\right]
$$

\subsection{Ballistic properties evaluation}

According to what mentioned, the independent ballistic properties that would be separately inspected were the linear burning rate (after $T_{S}$ estimation) and the temperature sensitivities. In addition, the dependent ballistic property that might be corrected was the pressure index (n). The value of $n$ was evaluated, at least, from the predicted burning rates at three pressure values (20, 70 and 120 bar). It was assumed that the formulations obeyed the De Saint Robert and Vieille law. The propellant temperature sensitivity of burning rate at assigned pressure $\sigma_{\mathrm{Pc}}$ was calculated under, ( 70 bar as the particular value of pressure), the assumption that its value not changed at upper or lower temperature conditions when compared to the reference temperature $T_{0}$. Then, the propellant temperature sensitivity of pressure at assigned blocking $\pi_{\mathrm{KL}}$ was calculated, $\pi_{\mathrm{KL}}=\sigma_{\mathrm{Pc}} / 1-\mathrm{n}$. The applied techniques to deal with the ballistic properties were:

1) To deal with $r$, the previously mentioned schemes were used, and iterative techniques were applied to estimate the propellant surface temperature in two steps. The first represented the preliminary approach and was applied between $T_{o}$ and $T_{f}$ where the convergence yielded 
the first value of the surface temperature $T_{s}$ (say $T_{1 s}$ ). The second represented the final approach, where $T_{d}$ was estimated (between $T_{o}$ and $T_{1 s}$ ) then $T_{f s}$ was calculated followed by solid and gas phases specifications corrections, and was re-applied between $T_{o}$ and $T_{f}$ where the convergence yielded the second value of the surface temperature $T_{s}\left(s a y T_{2 s}\right)$. Thus, the surface temperature $T_{s}$ was assumed to approximately equal the average value between $T_{1 \mathrm{~s}}$ and $\mathrm{T}_{2 \mathrm{~s}}$.

2) To deal with $\sigma_{\mathrm{Pc}}$, the following approach was applied ${ }^{[20,34]}$ :

a) Because the regression of the oxidizer was considered as the rate-controlling step in combustion then $\sigma_{\mathrm{Pc}}$ basic definition was simplified, under an initial temperature $\mathrm{T}_{\mathrm{o}}$ and pressure $\mathrm{P}_{\mathrm{c}} \approx 70$ bar, to:

$$
\sigma_{P_{c}}=\frac{d \ln \overline{m_{o x}}}{d T_{\text {o }}}
$$

b) By differentiating Equations (2, 3, and 10) and solving for $\sigma_{\mathrm{Pc}}$ in Equation (28), we obtained:

$$
\sigma_{P_{c}}=\frac{1+(1.25)\left(1-\beta_{F}\right)\left(\frac{\overline{Q_{A P}}}{C_{P}}\right) \cdot \alpha \cdot \overline{\xi_{A P}^{*}} \cdot \exp \left(-\overline{\xi_{A P}^{*}}\right)\left(\frac{\overline{E_{o x}}}{R T_{A P}^{2}}\right)}{\frac{R T_{s}^{2}}{\overline{E_{o x}}}+(1.25)\left(1-\beta_{F}\right)\left(\frac{\overline{Q_{A P}}}{C_{P}}\right) \cdot \alpha \cdot 2 \overline{\xi_{A P}^{*}} \cdot \exp \left(-\overline{\xi_{A P}^{*}}\right)}
$$

Where:

$$
\overline{E_{o x}}=\sum_{i=1}^{n} \alpha_{o x_{i}} E_{o x_{i}}
$$

3) If the calculated $n \geq 0.77$ then, it was corrected in an analogous manner to $\sigma_{P c}{ }^{[20]}$ :

$$
n=\frac{d \ln \overline{m_{o x}}}{d \ln P}=\delta /\left\{2+\left[\left(\frac{R T_{s}^{2}}{\overline{E_{o x}}}\right) /(1.25)\left(1-\beta_{F}\right)\left(\frac{\overline{Q_{A P}}}{C_{P}}\right) \cdot \alpha \cdot \overline{\xi_{A P}^{*}} \cdot \exp \left(-\overline{\xi_{A P}^{*}}\right)\right]\right\}
$$

A FORTRAN computer program was established for obtaining, by the previously described schemes, the linear burning rates and surface temperatures of the twenty Butalites formulations under this investigation. The propellant ingredients with their basic specifications represented the program main input data. The combustion equations were solved iteratively and no particular difficulty was encountered in the solution convergence. The program was compiled and applied to calculate the propellant surface temperature, linear burning rate and other ballistic properties.

\section{Discussions}

The specific surface areas of the solid ingredients (Table 2) were effective, especially, when compared with their theoretically calculated values. The ignition temperatures (Table 3) clarified that CC had the greatest effect and other ingredients effects $( \pm 2 \%)$ can be neglected. The thermal analytical measurements (Table 2) showed that the AP samples, (PU-binder samples), kinetic parameters at high and low conversions were in acceptable agreements with

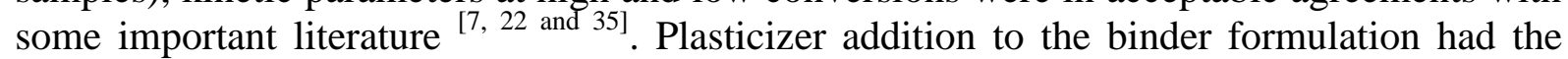
greatest effect on lowering the decomposition characteristic parameters. The higher the AP particle size the lower the decomposition kinetic parameters and the higher the automatically determined heats of gasification. The kinetic parameters variations at high conversion for both $\mathrm{AP}^{[11]}$ and PU-binder were introduced to the modified BDP model equations in this study. The ballistic properties (Tables 1 and 7) were discussed according to factors affecting combustion as follows:

1) The investigations for sub-group $\mathrm{AI}$ and sub-group BI showed the trend of increasing the linear burning rate when increasing AP content. Similar behavior was observed in all 
pressures from 20 to 120 bar. That was demonstrated due to the increase of the oxidizer volumetric solid loading through the propellant microstructure, the increase of the reaction ability to be more exothermic, and the increase of the propellant surface temperature.

2) The investigations for sub-group AII and sub-group BII showed a monotonous decrease in the burning rate when increasing the particle size in all inspected pressures due to the decrease of the oxidizer burning surface area.

3) For Sub-group AIII, Al was found to have a remarkable effect on the linear burning rate. The effect was similar in all pressures revealing an effective increase with Al content when compared to the burning rates evaluated for the non-aluminized fuel rich formulation AI-3. This latter phenomenon is not known for regular propellants where burning rates are not much affected by $\mathrm{Al}$ presence (added at the expense of the oxidizer) and may be attributed to $\mathrm{Al}$ appreciable influence on the flame temperature ${ }^{[36,37]}$.

4) For Sub-group AIV and Sub-group AV, effect of the burning rate accelerator (CC) was investigated. $\mathrm{CC}$ exhibited a moderate increase in the evaluated linear burning rate for the non-Al-formulations (AIV) due to the exothermic reaction at the CC-AP interface which lowered the oxidizer ignition temperature, increased its sensitivity to heat, reduced the activation energy required to start the deflagration reaction on the propellant surface and consequently increased the reaction rate through the propellant solid-gas interface. However, CC exhibited sharp increase in the burning rates when changing to Alformulations (AV), due to $\mathrm{Al}$ additional effect.

5) For Sub-group BIII, effect of $\mathrm{CC}$ and $\mathrm{CaCO}_{3}$ addition was compared. BIII-3 formulation predictions were marked as coincident with its practical results at $25^{\circ} \mathrm{C}$, which reinforced $\mathrm{CaCO}_{3}$ treatment methodology.

6) Formulation BIV revealed that the prediction ability of the ballistic properties for an independent high burning rate propellant formulation was verified. 
Table 7 Formulations predicted data and their prediction accuracy levels

\begin{tabular}{|c|c|c|c|c|c|c|c|c|c|c|c|}
\hline \multirow{3}{*}{ No. } & \multirow{2}{*}{\multicolumn{3}{|c|}{$\begin{array}{c}T_{s} \\
(\mathrm{~K})\end{array}$}} & \multirow{3}{*}{ Parameter } & \multirow{3}{*}{$\mathrm{n}$} & \multirow{3}{*}{$\begin{array}{l}\text { Mean } \\
\sigma_{P_{c}} \\
\left(/^{\circ} \mathrm{C}\right)\end{array}$} & \multicolumn{5}{|c|}{$\mathrm{r}(\mathrm{mm} / \mathrm{s})$} \\
\hline & & & & & & & \multicolumn{2}{|l|}{$-30^{\circ} \mathrm{C}$} & \multicolumn{2}{|l|}{$25^{\circ} \mathrm{C}$} & \multirow{2}{*}{$\frac{50^{\circ} \mathrm{C}}{70 / \mathrm{bar}}$} \\
\hline & $\begin{array}{c}20 \\
\text { bar }\end{array}$ & $\begin{array}{c}70 \\
\text { bar }\end{array}$ & $\begin{array}{l}120 \\
\text { bar }\end{array}$ & & & & 70/bar & 20/bar & 70/bar & 120/bar & \\
\hline \multirow{3}{*}{ AI-1 } & \multirow[b]{2}{*}{298.1} & \multirow[b]{2}{*}{590.0} & \multirow[b]{2}{*}{645.5} & Practical: & 0.120 & 0.01300 & \multirow[b]{2}{*}{0.165} & & 0.260 & 0.277 & 0.360 \\
\hline & & & & $\begin{array}{l}\text { Theoretical: } \\
\text { Accuracy (\%): }\end{array}$ & $\begin{array}{l}0.226 \\
+88.3\end{array}$ & $\begin{array}{c}0.00943 \\
-27.5\end{array}$ & & 0.208 & $\begin{array}{l}0.277 \\
+6.5\end{array}$ & $\begin{array}{l}0.313 \\
+13.0\end{array}$ & $\begin{array}{l}0.350 \\
-2.8\end{array}$ \\
\hline & & & & Practical: & 0.270 & 0.00360 & & 0.378 & 0.530 & 0.613 & 0.580 \\
\hline $\mathrm{AI}-2$ & 380.8 & 805.5 & 833.4 & $\begin{array}{l}\text { Theoretical: } \\
\text { Accuracy (\%): }\end{array}$ & $\begin{array}{l}0.267 \\
-1.1\end{array}$ & $\begin{array}{c}0.00439 \\
+\mathbf{2 1 . 9}\end{array}$ & 0.387 & $\begin{array}{l}0.353 \\
-6.6\end{array}$ & $\begin{array}{l}0.493 \\
-7.0\end{array}$ & $\begin{array}{l}0.569 \\
-7.2\end{array}$ & $\begin{array}{l}0.550 \\
-5.2\end{array}$ \\
\hline & & & & Practical: & 0.340 & 0.00565 & 0.790 & 0.725 & 1.110 & 1.333 & 1.260 \\
\hline AI-3 & 430.9 & 813.3 & 836.2 & Theoretical: & 0.335 & 0.00401 & 0.815 & 0.668 & 1.016 & 1.217 & 1.123 \\
\hline & & & & Accuracy (\%): & -1.5 & -29.0 & +3.2 & -7.9 & -8.5 & -8.7 & -10.9 \\
\hline & & & & Practical: & 0.280 & 0.00660 & & 0.711 & 1.010 & 1.175 & 1.190 \\
\hline AII-1 & 437.9 & 817.3 & 839.1 & Theoretical: & 0.347 & 0.00388 & 0.777 & 0.623 & 0.962 & 1.159 & 1.060 \\
\hline & & & & Accuracy (\%): & +23.9 & -41.2 & & -12.4 & -4.8 & -1.4 & -10.9 \\
\hline & & & & Practical: & 0.310 & 0.00550 & & 0.604 & 0.890 & 1.052 & 1.020 \\
\hline AII-2 & 445.0 & 821.0 & 842.0 & Theoretical: & 0.360 & 0.00377 & 0.694 & 0.544 & 0.854 & 1.036 & 0.938 \\
\hline & & & & Accuracy (\%): & +16.1 & -31.5 & & -9.9 & -4.0 & -1.5 & -8.0 \\
\hline & & & & Practical: & 0.260 & 0.00690 & 2.170 & 1.848 & 2.560 & 2.945 & 2.820 \\
\hline AIII-1 & 640.9 & 868.2 & 880.6 & Theoretical: & 0.257 & 0.00289 & 2.329 & 1.979 & 2.730 & 3.135 & 2.935 \\
\hline & & & & Accuracy (\%): & -1.2 & -58.1 & +7.3 & +7.1 & +6.6 & +6.5 & +4.1 \\
\hline & & & & Practical: & 0.220 & 0.00180 & 3.820 & 3.150 & 4.150 & 4.672 & 4.370 \\
\hline AIII-2 & 807.0 & 895.1 & 905.1 & Theoretical: & 0.203 & 0.00260 & 3.525 & 3.151 & 4.066 & 4.537 & 4.338 \\
\hline & & & & Accuracy (\%): & -7.7 & +44.4 & -7.7 & +0.03 & -2.0 & -2.9 & -0.7 \\
\hline & & & & Practical: & 0.230 & 0.00560 & 1.420 & 1.282 & 1.710 & 1.936 & 2.080 \\
\hline AIV-1 & 502.9 & 822.6 & 837.5 & Theoretical: & 0.170 & 0.00332 & 1.506 & 1.461 & 1.807 & 1.980 & 1.963 \\
\hline & & & & Accuracy (\%): & -26.1 & -40.7 & +6.1 & +14.0 & +5.7 & +2.3 & -5.6 \\
\hline & & & & Practical: & 0.280 & 0.00570 & 1.850 & 1.662 & 2.360 & 2.744 & 2.810 \\
\hline AIV-2 & 580.5 & 816.1 & 827.7 & Theoretical: & 0.283 & 0.00307 & 2.120 & 1.761 & 2.510 & 2.923 & 2.710 \\
\hline & & & & Accuracy (\%): & +1.1 & -46.1 & +14.6 & +6.0 & +6.4 & +6.5 & -3.6 \\
\hline & & & & Practical: & 0.190 & 0.00285 & 2.670 & 2.483 & 3.150 & 3.490 & 3.370 \\
\hline AV-1 & 719.3 & 853.8 & 864.5 & Theoretical: & 0.307 & 0.00281 & 2.874 & 2.284 & 3.354 & 3.957 & 3.598 \\
\hline & & & & Accuracy (\%): & +61.6 & -1.4 & +7.6 & -8.0 & +6.5 & +13.4 & +6.8 \\
\hline & & & & Practical: & 0.200 & 0.00280 & 3.290 & 2.919 & 3.750 & 4.177 & 4.060 \\
\hline AV-2 & 747.3 & 833.2 & 842.7 & Theoretical: & 0.309 & 0.00277 & 3.500 & 2.768 & 4.076 & 4.814 & 4.368 \\
\hline & & & & Accuracy (\%): & +54.5 & -1.1 & +6.4 & -5.2 & +8.7 & +15.3 & +7.6 \\
\hline & & & & Practical: & 0.340 & & & 4.448 & 6.810 & 8.180 & \\
\hline BI-1 & 876.5 & 945.3 & 954.4 & Theoretical: & 0.300 & 0.00221 & 6.363 & 4.933 & 7.187 & 8.450 & 7.596 \\
\hline & & & & Accuracy (\%): & -11.8 & & & +10.9 & +5.5 & +3.3 & \\
\hline & & & & Practical: & 0.390 & & & 4.540 & 7.400 & 9.131 & \\
\hline BI-2 & 883.7 & 952.6 & 961.8 & Theoretical: & 0.416 & 0.00218 & 7.187 & 4.814 & 8.103 & 10.138 & 8.557 \\
\hline & & & & Accuracy (\%): & +6.7 & & & +6.0 & +9.5 & +11.0 & \\
\hline & & & & Practical: & 0.440 & & & 5.786 & 10.040 & 12.727 & \\
\hline BI-3 & 891.7 & 961.0 & 970.3 & $\begin{array}{l}\text { Theoretical: } \\
\text { Accuracy (\%): }\end{array}$ & $\begin{array}{l}0.464 \\
+5.5\end{array}$ & 0.00215 & 8.247 & $\begin{array}{l}5.191 \\
-10.3\end{array}$ & $\begin{array}{l}9.280 \\
-7.6\end{array}$ & $\begin{array}{c}11.914 \\
-6.4\end{array}$ & 9.791 \\
\hline & & & & Practical: & 0.310 & 0.00132 & 6.270 & 4.578 & 6.750 & 7.978 & 6.980 \\
\hline BII-1 & 892.9 & 963.6 & 972.9 & Theoretical: & 0.352 & 0.00211 & 6.319 & 4.568 & 7.097 & 8.578 & 7.482 \\
\hline & & & & Accuracy (\%): & +13.5 & +59.8 & +0.8 & -0.2 & +5.1 & +7.5 & +7.2 \\
\hline & & & & Practical: & 0.280 & 0.00127 & 6.890 & 5.197 & 7.380 & 8.582 & 7.620 \\
\hline BII-2 & 891.7 & 962.1 & 971.4 & Theoretical: & 0.363 & 0.00212 & 6.502 & 4.635 & 7.307 & 8.888 & 7.705 \\
\hline & & & & Accuracy (\%): & +29.6 & +66.9 & -5.6 & -10.8 & -1.0 & +3.6 & +1.1 \\
\hline & & & & Practical: & 0.400 & 0.00208 & 6.920 & 4.695 & 7.750 & 9.615 & 8.160 \\
\hline BIII-1 & 882.6 & 950.7 & 959.7 & Theoretical: & 0.301 & 0.00219 & 6.703 & 5.186 & 7.560 & 8.890 & 7.985 \\
\hline & & & & Accuracy (\%): & -24.8 & +5.3 & -3.1 & +10.5 & -2.5 & -7.5 & -2.1 \\
\hline & & & & Practical: & 0.370 & 0.00159 & 10.960 & 7.517 & 11.950 & 14.587 & 12.430 \\
\hline BIII-2 & 877.8 & 945.5 & 954.5 & Theoretical: & 0.277 & 0.00213 & 10.669 & 8.478 & 11.996 & 13.928 & 12.652 \\
\hline & & & & Accuracy (\%): & -25.1 & +34.0 & -2.7 & +12.8 & +0.4 & -4.5 & +1.8 \\
\hline & & & & Practical: & 0.300 & 0.00082 & 6.860 & 4.931 & 7.180 & 8.440 & 7.330 \\
\hline BIII-3 & 878.7 & 946.7 & 955.8 & Theoretical: & 0.306 & 0.00220 & 6.331 & 4.868 & 7.144 & 8.427 & 7.548 \\
\hline & & & & Accuracy (\%): & +2.0 & +168.3 & -7.7 & -1.3 & -0.5 & -0.2 & +3.0 \\
\hline & & & & Practical: & 0.230 & & & 13.449 & 17.940 & 20.308 & \\
\hline BIV & 866.6 & 934.0 & 943.0 & Theoretical: & 0.341 & 0.00205 & 16.627 & $\begin{array}{c}12.143 \\
-97\end{array}$ & 18.613 & 22.368 & 19.593 \\
\hline
\end{tabular}

The previous table provided us with complete visions about the accuracy levels accompanied our predictions. Generally, the all-ballistic properties predictions were marked as approved. Some of $\mathrm{n}$ and $\sigma_{\mathrm{Pc}}$ predicted results, as a variation behavior, were marked as fair. Many of 
them (64\%) as specific values for comparison with the experimental results may be marked as not fair, but when inspected their effects over the predicted linear burning rates at different temperatures $\left(-30,25\right.$ and $\left.50^{\circ} \mathrm{C}\right)$ and pressures (20-120 bar) they were marked as applicable. Therefore, following the international acceptance margins ${ }^{[8,22]}$ that based on the direct comparisons between the theoretically predicted and practically evaluated linear burning rates at 70 bar represented the best way to judge validity of the ballistic properties predictions. Evidently, the prediction accuracy levels were listed in Table 7.

From the modifications applied to the BDP model, it was very important to clarify the following:

1) The modified model really liberated itself from its emphasis on the flame standoff distances under the assumption suggested by Summerfield et al ${ }^{[20,24]}$. However, under this assumption (to guaranteed iterations continuation over the model equations until

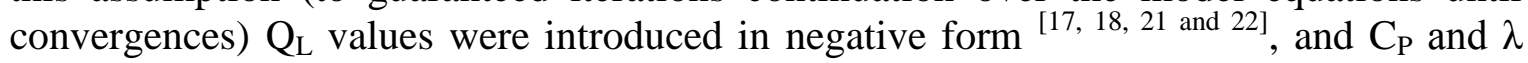
assumed to equal the half-average values calculated before for solids and gases combination.

2) The predicted densities (Table 5) were within deviations from about -2.7 to $+0.9 \%$ when compared to the practical results (Table 1) which provided them with the required certainty.

3) The determined pre-exponential factor in " $\mathrm{s}^{-1 "}$ for AP, (PU-binder), samples was assumed to have the same values when converted to mass flux in " $\mathrm{g} \mathrm{cm}^{-2} \mathrm{~s}^{-1 "}$ because the evaluated kinetic parameters under high conversion conditions were close together.

4) The pressure value of 70 bar represented the standard condition value in this study where

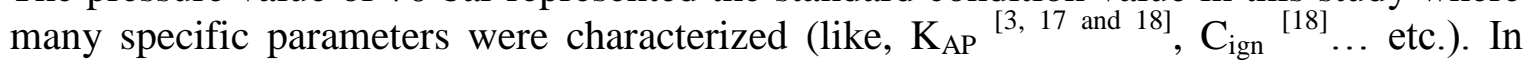
addition, under this pressure value with variant equivalence ratios, the instantaneous regression rates of pyrolysis for both AP-oxidizer and hydrocarbon-fuel binders are intrinsically oscillated about a single value or approximately coincident together. Where, the overall ratio of their regression rates tends to unity suggesting that the pyrolysis of the mixture approaches a steady state situation ${ }^{[38]}$. Moreover, it represents the international value at which the propellant specifications are characterized and compared ( $70 \mathrm{bar} \approx 70$ $\mathrm{atm} \approx 1000 \mathrm{psi})^{[8,36]}$.

5) The used one-dimensional limited temperature profile with variant decomposition characteristic parameters to estimate $\mathrm{T}_{\mathrm{s}}$ verified the requirements leaded to predict the ballistic properties. Herein, we considered that, some $\mathrm{T}_{\mathrm{s}}$ values in Group-A compositions, especially at 20 bar (Table 7), were said to be an art rather than a science.

\section{Conclusions}

Solid and gas phases calculations provided the study objective with the required light for its solution convergence. The linear burning rate predictions, without the BDP model multiple flame standoff distances, were verified using an easy abstention technique over the combustion zone. The used reference data of $\beta_{\mathrm{F}}$ verified applicable reflections to the overall pattern but still require separate investigations over AP/HTPB-based PU-binder formulations. The $\mathrm{S}_{\mathrm{ox}} / \mathrm{S}_{\mathrm{O}}$ ratios calculation and correction base, verified passable (moderate extent) reflections to the predicted linear burning rates. They require wider calculations for the all $\mathrm{h} / \mathrm{D}_{\mathrm{o}}$ ratios regime and deeper penetration to the propellant surface geometry at different pressures under microscopic levels. The additives ( $\mathrm{Al}, \mathrm{CB}, \mathrm{CC}$, and $\mathrm{CaCO}_{3}$ ) passive incorporation methodology to the BDP model was marked as fair. The predicted linear burning rates were verified the international acceptance margins in this field ${ }^{8,22]}$. Evidently, about $98 \%$ of the results were within $\pm 15 \%$ deviation, $81 \%$ within $\pm 10 \%$, and $43 \%$ within \pm $6 \%$ at $25{ }^{\circ} \mathrm{C}$ and $20-120$ bar. In addition, $100 \%$ were within $\pm 10 \%$ deviation and $56 \%$ within 
$\pm 6 \%$ at $25{ }^{\circ} \mathrm{C}$ and 70 bar. Moreover, $100 \%$ were within $\pm 15 \%$ deviation, $89 \%$ within $\pm 10 \%$, and $54 \%$ within $\pm 6 \%$ at $-30{ }^{\circ} \mathrm{C},+50{ }^{\circ} \mathrm{C}$ and 70 bar. The international acceptance margins ${ }^{[8]}$ between linear burning rate theoretical predictions and practical evaluations at 70 bar were verified for the whole Butalites formulations under this investigation, about $94 \%$ of the all-70 bar predictions were within $\pm 10 \%$ error range. The pressure index and temperature sensitivities prediction values were applicable for the preliminary studies. The verified accuracy levels provided us with the required information about the used technique validity and the applied modifications applicability to the basic BDP model ${ }^{[17]}$, especially, if compared to similar studies ${ }^{[20-22]}$.

\section{References}

[1] G. P. Sutton, Rocket Propulsion Elements, Sixth Edition, New York: John Wiley \& Sons, Inc. (1992) Chapter 13.

[2] Y. Timnat, Advanced Chemical Rocket Propulsion, London: Academic Press (1987) Chapter 3.

[3] K. Kuo, M. Summerfield, Fundamentals of Solid Propellant Combustion, New York: AIAA, Inc. (1984) Chapter 8.

[4] H. Singh, H. Shekhar, Problems Associated with the Combustion Modeling of Solid Rocket Propellants, Printed by Printwell, India (2008).

[5] Solid propellant selection and characterization, NASA SP-8064, Space Vehicle Design Criteria, NASA, Washington, DC, USA (1971).

[6] A. Davenas, Solid Rocket Propulsion Technology, Oxford: Pergamon Press (1993) Chapter 4.

[7] G. Lengellé, J. Duterque, J.F. Trubert, Combustion of Solid Propellants, RTO-EN-023, ONERA, France (2004).

[8] T. Deyu, Z. Wei, Burning Rate Estimation of AP/AL/HTPB Propellants, Germany, ICT (1989) 54-1: 54-4.

[9] A. Davenas, Solid Rocket Propulsion Technology, Oxford: Pergamon Press (1993) Chapter 10.

[10] P. Simon, Isoconversional methods: Fundamentals, Meaning and Application, Thermal Analysis and Calorimetry (2004) 76: 123-132.

[11] Abdel-Wareth W. M., X. Xu, Ammonium Perchlorate Decomposition Characteristic Parameters Determination, A Simplified Approach, India, New Delhi, International Conference on Mechanical and Aerospace Engineering, March 21-23 (2011) 570-574.

[12] S. I. Stoliarov, R. N. Walters, Determination of the Heats of Gasification of Polymers Using DSC, DOT/FAA/AR-TN07/62, SRA International, Inc., USA (2007).

[13] C. L. Yaws, Handbook of Thermal Conductivity, Inorganic Compounds and Elements, Volume 4, Gulf Publishing Company (1995).

[14] M. Binnewies, E. Milke, Thermo-chemical Data of Elements and Compounds, Germany: Wiley-Vch Publishing Co. (2002).

[15] P. Heira, J. Campos, Some Rules for the Design of High Solid Loading Composite Solid Propellants, Germany, ICT (1995) 55-1: 55-14. 
[16] S.Gordon, B.J. Mcbride, Computer Program for Calculation of Complex Chemical Equilibrium Compositions and Applications, NASA RP 1311, Part II: Users Manual and Program Descriptions, USA (1996).

[17] M. W. Beckstead, R. L. Derr, C. F. Price, A Model of Composite Solid-Propellant Combustion Based on Multiple Flames, AIAA Journal (1970) 8 (12): 2200-2207.

[18] M. Iqbal, W. Liang, Propellant Burning Rate Calculations with Improved Predictions, Chinese Journal of Solid Rocket Technology (2002) 25 (1): 51-54.

[19] M. Nikazar, M. B. Bagherpour, B. Dabir, The Use of Fractal for Prediction of Burning Rate of Composite Solid Propellants, Journal of Thermal Science (2000) 9 (4): 361364.

[20] V. Swaminathan, M. Soosaimarian, Burning Rate Evaluation of Composite Solid Propellants - A Simplified Approach, Propellants and Explosives (1981) 6: 37-41.

[21] M. Iqbal, W. Liang, Burning Rate Calculations of Wide Distribution Ammonium Perchlorate Composite Propellants, AIAA (2006-1161).

[22] L. Shi-liang, Study on Primary Combustion Characteristics of Magnesium-based Hydro-reactive Metal Fuel Used for Water Ramjet, National University of Defense Technology, Changsha, Hunan, P.R.China, Ph. D. Thesis, Nov. (2009).

[23] N. Kubota, Thermo-Chemical Aspects of Combustion, Germany: Wiley-Vch Publishing Co. (2002) Chapter 3.

[24] J. A. Steinz, P. L. Stang, M. Summerfield, The Burning Mechanism of Ammonium Perchlorate-Based Composite Solid Propellants, Aerospace and Mechanical Science Report No. 830, Princeton University (1969).

[25] D. Baker, Investigation of Composite Solid Propellant Burning Rate Temperature Sensitivity, Ph. D. Thesis, Purdue University (1973).

[26] S. Krishnan, R. Jeenu, Combustion Characteristics of AP/HTPB Propellants with Burning Rate Modifiers, Journal of Propulsion and Power (1992) 8 (4): 748-755.

[27] K. Kuo, M. Summerfield, Fundamentals of Solid Propellant Combustion, New York: AIAA, Inc. (1984) Chapter 9.

[28] T. Bazyn, H. Krier, N. Glumac, Oxidizer and Pressure Effects on the Combustion of 10- $\mu \mathrm{m}$ Aluminum Particles, Journal of Propulsion and Power (2005) 21 (4): 577-581.

[29] J. Zhi, W. Tian-Fang, L. Shu-Fen, Z. Feng-Qi, L. Zi-Ru, Y. Cui-Mei, L. Yang, L. Shang-Wen, Z. Gang-Zhui, Thermal Behavior of Ammonium Perchlorate and Metal Powders of Different Grades, Thermal Analysis and Calorimetry (2006) 85 (2): 315320.

[30] J. Bouillard, A. Crossley, J. Dien, P. Dobson, T. Klepping, A. Vignes, Safety Parameter Characterization Techniques for Nanoparticles, DR-152-200802-2, European Union (2008).

[31] K. Fujimura, A. Miyaka, The Effect of Specific Surface Area of TiO2 on the Thermal Decomposition of Ammonium Perchlorate, Thermal Analysis and Calorimetry (2010) 99: 27-31.

[32] L. Zivorad, Burning Rate of a Tri-modal Composite Rocket Propellant, J. Propulsion (1990) 6 (5): 515-518. 
[33] X. Xingcai, W. Zhujun, Research on Lowering the Pressure Exponent of HTPB Propellant at High Pressure, Journal of Propulsion Technology (1993) (6): 73-76.

[34] N. Cohen, D. Flanigan, Mechanisms and Models of Solid Propellant Burn Rate Temperature Sensitivity - A Review, AIAA (1984-0286).

[35] K. N. Ninan, K. Krishnan, Thermal Decomposition Kinetics of Polybutadiene Binders, J. Spacecraft (1982) 19 (1): 92-94.

[36] Abdel-Wareth W. M, Study of the Combustion Behavior of the Low Oxygen Content CSRP, Cairo University, Faculty of Engineering, Cairo, Egypt, M. Sc. Thesis (2006).

[37] A. Shalom, A. Gany, Flammability Limits and Ballistic Properties of Fuel-Rich Propellants, Propellants, Explosives, Pyrotechnics (1991) 16: 59-64.

[38] Preetham, S. R. Chakravarthy, Effect of Heterogeneity of Solid Propellants on Their Intrinsic Stability of Pyrolysis, AIAA (2004-240).

\section{Appendix 1}

1) AP particle size $[\mathrm{x}(\mu \mathrm{m})]$ and heat of gasification $[\mathrm{y}(\mathrm{cal} / \mathrm{g})]$ :

$$
\mathrm{y}=4.0641 \operatorname{Ln}(\mathrm{x})+95.071 \rightarrow \mathrm{R}^{2}=0.89
$$

2) PU-binder $\mathrm{NCO} / \mathrm{OH}$ ratio $[\mathrm{x}]$ and heat of pyrolysis $[\mathrm{y}(\mathrm{cal} / \mathrm{g})]$ :

$$
\mathrm{y}=-17.3 \mathrm{x}+292 \rightarrow \mathrm{R}^{2}=1
$$

3) PU-binder $\mathrm{IM} / \mathrm{OH}$ ratio $[\mathrm{x}]$ and heat of pyrolysis $[\mathrm{y}(\mathrm{cal} / \mathrm{g})]$ :

$$
\mathrm{y}=-21.6 \mathrm{x}+285.5 \rightarrow \mathrm{R}^{2}=1
$$

4) PU-binder DOZ/HTPB ratio [x] and heat of pyrolysis [y (cal/g)]:

$$
\mathrm{y}=-271.2 \mathrm{x}+274.7 \rightarrow \mathrm{R}^{2}=1
$$

5) AP specific surface $[\mathrm{x}(\mu \mathrm{m})]$ and activation energy [y (kcal/mole $)]$ :

$$
\mathrm{y}=0.3723 \operatorname{Ln}(\mathrm{x})+27.336 \rightarrow \mathrm{R}^{2}=0.9783
$$

6) AP specific surface $[\mathrm{x}(\mu \mathrm{m})]$ and pre-exponential factor $[\mathrm{y}(/ \mathrm{s})]$ :

$$
\mathrm{y}=10^{6} .(1.1588 \operatorname{Ln}(\mathrm{x})+5.7905) \rightarrow \mathrm{R}^{2}=0.9831
$$

7) PU-binder $\mathrm{NCO} / \mathrm{OH}$ ratio $[\mathrm{x}]$ and activation energy $[\mathrm{y}(\mathrm{kcal} / \mathrm{mole})]$ :

$$
y=-0.33 x+45.59 \rightarrow R^{2}=1
$$

8) PU-binder $\mathrm{NCO} / \mathrm{OH}$ ratio $[\mathrm{x}]$ and pre-exponential factor $[\mathrm{y}(/ \mathrm{s})]$ :

$$
\mathrm{y}=10^{11} \cdot(-0.61 \mathrm{x}+4.31) \rightarrow \mathrm{R}^{2}=1
$$

9) PU-binder IM/OH ratio [x] and activation energy [y (kcal/mole)]:

$$
y=-0.48 x+45.5 \rightarrow R^{2}=1
$$

10) PU-binder $\mathrm{IM} / \mathrm{OH}$ ratio $[\mathrm{x}]$ and pre-exponential factor $[\mathrm{y}(/ \mathrm{s})]$ :

$$
\mathrm{y}=10^{11} .(-0.92 \mathrm{x}+4.16) \rightarrow \mathrm{R}^{2}=1
$$

11) PU-binder DOZ/HTPB ratio [x] and activation energy [y ( $\mathrm{kcal} / \mathrm{mole})]$ :

$$
y=-2.96 x+45.26 \rightarrow R^{2}=1
$$

12) PU-binder DOZ/HTPB ratio $[\mathrm{x}]$ and pre-exponential factor $[\mathrm{y}(/ \mathrm{s})]$ :

$$
\mathrm{y}=10^{11} \cdot(-5.12 \mathrm{x}+3.7) \rightarrow \mathrm{R}^{2}=1
$$




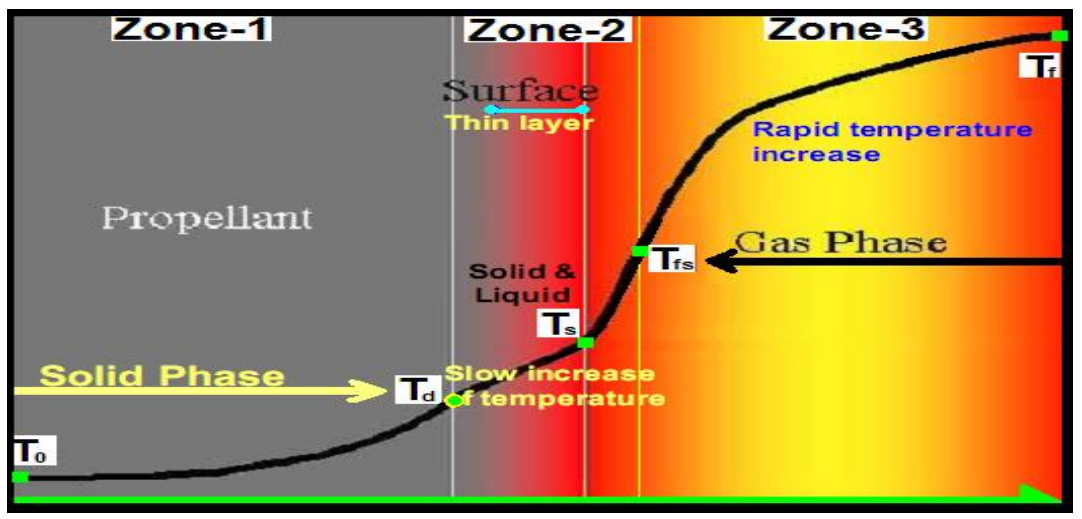

Figure 1 Modified combustion wave of an AP-based composite propellant.

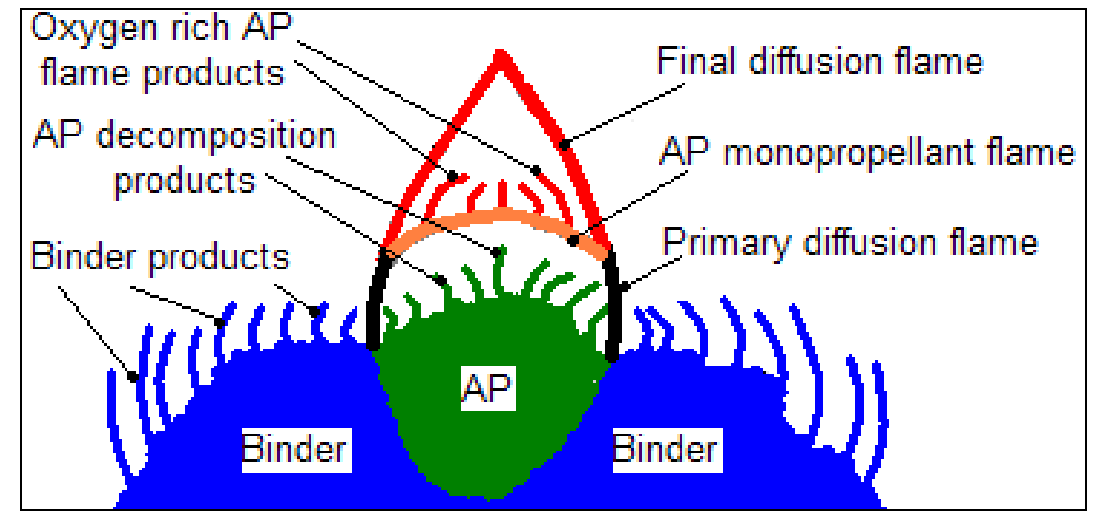

Figure 2 Multiple flames in the BDP model.

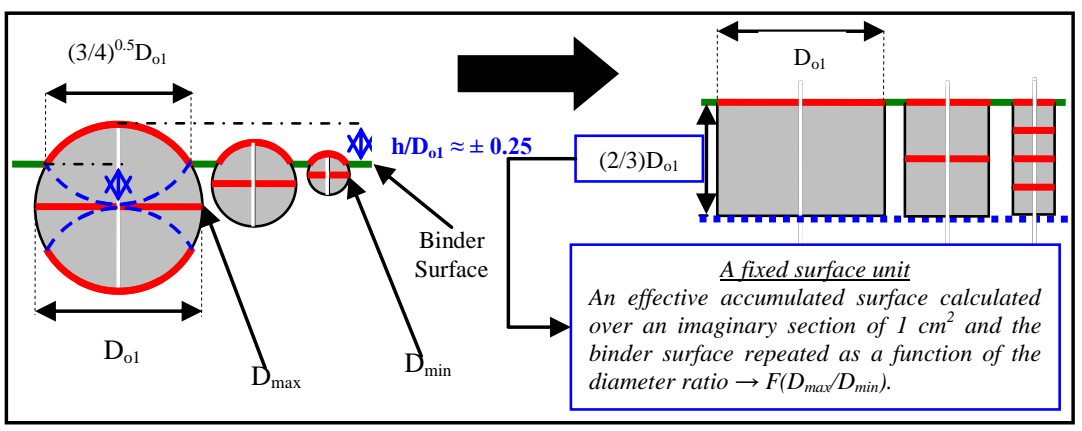

Figure 3 AP-particles, assumed idealized geometry. 


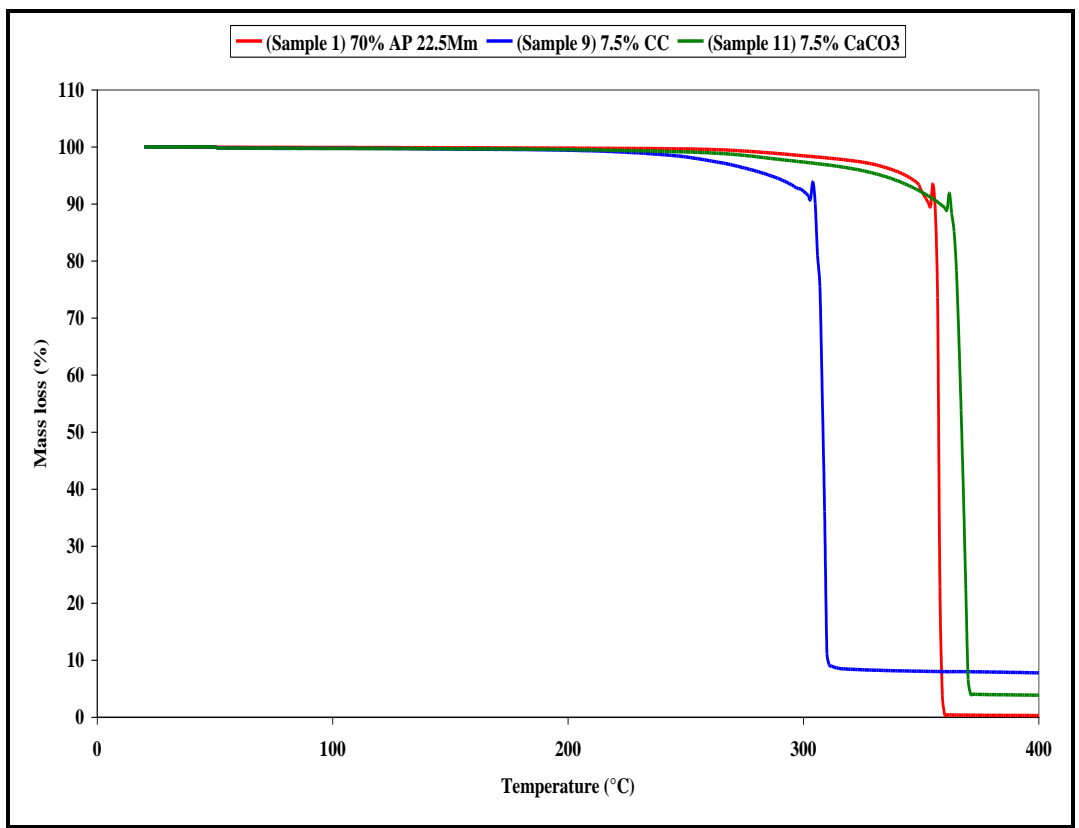

Figure 4 Mass sudden degradation steps $\left(T_{i g}\right)$ of some propellant mixtures.

\section{Nomenclature}

$\begin{array}{ll}\mathrm{A}_{\mathrm{f}} & \text { Binder Pre-exponential factor } \\ \mathrm{A}_{\mathrm{ox}} & \text { Oxidizer Pre-exponential factor } \\ \mathrm{C}_{\mathrm{Al}} & \text { Al specific heat capacity } \\ \mathrm{C}_{\mathrm{AP}} & \text { AP averaged specific heat } \\ \mathrm{C}_{\mathrm{CaCO} 3} & \mathrm{CaCO}_{3} \text { specific heat capacity } \\ \mathrm{C}_{\mathrm{CB}} & \mathrm{CB} \text { specific heat capacity } \\ \mathrm{C}_{\mathrm{CC}} & \text { CC specific heat } \\ \mathrm{C}_{\mathrm{ign}} & \text { Delay constant } \\ \mathrm{C}_{\mathrm{P}} & \text { Average heat capacity for the solids and the gases } \\ \mathrm{E}_{\mathrm{ox}} & \text { Oxidizer activation energy } \\ \mathrm{E}_{\mathrm{f}} & \text { Binder activation energy } \\ \mathrm{F}_{\mathrm{CCi}} & \text { The ith-grade oxidizer mass flux modification factor based on } \mathrm{CC} \\ & \text { incorporation } \\ \mathrm{h}_{\mathrm{f}} & \text { Al heat of fusion } \\ \mathrm{M}_{\mathrm{CaO}} / \mathrm{M}_{\mathrm{CaCO} 3} & \text { CaO to CaCO } 3 \text { molecular weight ratio }(\approx 0.56) \\ \mathrm{m}_{\mathrm{Al}} & \text { Al mass flux } \\ \mathrm{m}_{\mathrm{CB}} & \text { CB mass flux } \\ \mathrm{m}_{\mathrm{f}} & \text { Fuel binder mass flux } \\ \mathrm{m}_{\mathrm{ox}} & \text { Oxidizer mass flux } \\ \mathrm{m}_{\mathrm{T}} & \text { Total mass flux of the propellant } \\ \mathrm{n} & \text { Propellant pressure index } \\ \text { ox }_{\mathrm{i}} & \text { AP grade (i) with pre-defined Sauter mean diameter } \mathrm{D}_{\mathrm{oi}} \\ \mathrm{P}=\mathrm{P}_{\mathrm{c}} & \text { Combustion pressure } \\ \mathrm{Q}_{\mathrm{AP}} & \text { Heat release associated with the AP flame conditions } \\ \mathrm{Q}_{\mathrm{CaCO} 3} & \text { CaCO } 3 \text { heat of decomposition to CaO } \\ \mathrm{Q}_{\mathrm{FF}} & \text { Heat release associated with the final flame conditions } \\ \mathrm{Q}_{\mathrm{fuel}} & \text { Heat of pyrolysis of the fuel binder } \\ & \end{array}$


$Q_{L} \quad$ Heat of gasification of the oxidizer

$\mathrm{Q}_{\mathrm{PF}} \quad$ Heat release associated with the primary flame

$\mathrm{R} \quad$ Universal gas constant

$\mathrm{r} \quad$ Linear burning rate

$\mathrm{r}_{\mathrm{f}} \quad$ Binder-burning rate

$\mathrm{r}_{\mathrm{ox}} \quad$ Oxidizer-burning rate

$\mathrm{S}_{\mathrm{f}} \quad$ Fuel binder surface area

$\mathrm{S}_{\mathrm{o}} \quad$ Total surface area of the propellant

$\mathrm{S}_{\mathrm{Ox}} \quad$ Oxidizer surface area

$\mathrm{T}_{\mathrm{AP}} \quad$ AP adiabatic flame temperature

$t_{\text {ign }} \quad$ AP ignition delay time

$\Delta \mathrm{H}_{\text {fuel }} \quad$ Fuel binder enthalpy of formation

$\alpha$ Oxidizer weight fraction

$\alpha_{\mathrm{CaCO} 3} \quad \mathrm{CaCO}_{3}$ effective loading fraction to the oxidizer-fuel binder combination

$\alpha_{\mathrm{CC}} \quad \mathrm{CC}$ effective loading fraction to the oxidizer-binder combination

$\alpha_{\text {oxi }} \quad$ The $i^{\text {th }}$-grade oxidizer fraction of the total oxidizer in the propellant formulation

$\beta_{\mathrm{F}} \quad$ Fraction of the oxidizing reactants that react in the primary diffusion flame

$\rho_{\mathrm{f}} \quad$ Fuel binder density

$\rho_{\mathrm{ox}} \quad$ Oxidizer density

$\rho_{\mathrm{P}} \quad$ Propellant density

$\xi_{\mathrm{AP}}^{*} \quad$ AP flame non-dimensional standoff distance

$\xi_{\mathrm{FF}}^{*} \quad$ Final flame non-dimensional standoff distance

$\xi_{\mathrm{PF}}^{*} \quad$ Primary flame non-dimensional standoff distance

$\lambda \quad$ Thermal conductivity (average of solids and gases) 